NBER WORKING PAPER SERIES

\title{
COMPETITION AND INNOVATION: \\ AN INVERTED U RELATIONSHIP
}

\author{
Philippe Aghion \\ Nicholas Bloom \\ Richard Blundell \\ Rachel Griffith \\ Peter Howitt
}

Working Paper 9269

http://www.nber.org/papers/w9269

\author{
NATIONAL BUREAU OF ECONOMIC RESEARCH \\ 1050 Massachusetts Avenue \\ Cambridge, MA 02138 \\ October 2002
}

The authors would like to thank Daron Acemoglu, Tim Bresnahan, Wendy Carlin, Paul David, Janice Eberly, Dennis Ranque, Robert Solow, Manuel Trajtenberg, Alwyn Young, John Van Reenen and participants at CIAR, Harvard and MIT. Financial support for this project was provided by the ESRC Centre for the Microeconomic Analysis of Fiscal Policy at the IFS. The data was developed with funding from the Leverhulme Trust. The views expressed herein are those of the authors and not necessarily those of the National Bureau of Economic Research.

(C) 2002 by Philippe Aghion, Nicholas Bloom, Richard Blundell, Rachel Griffith, and Peter Howitt. All rights reserved. Short sections of text, not to exceed two paragraphs, may be quoted without explicit permission provided that full credit, including (C) notice, is given to the source. 
Competition and Innovation: An Inverted U Relationship Philippe Aghion, Nicholas Bloom, Richard Blundell, Rachel Griffith, and Peter Howitt NBER Working Paper No. 9269

October 2002

JEL No. O0, L1

\section{ABSTRACT}

This paper investigates the relationship between product market competition (PMC) and innovation. A growth model is developed in which competition may increase the incremental profit from innovating; on the other hand, competition may also reduce innovation incentives for laggards. There are four key predictions. First, the relationship between product market competition (PMC) and innovation is an inverted U-shape. Second, the equilibrium degree of technological 'neck-andneckness' among firms should decrease with PMC. Third, the higher the average degree of 'neckand-neckness' in an industry, the steeper the inverted-U relationship. Fourth, firms may innovate more if subject to higher debt-pressure, especially at lower levels of PMC. We confront these predictions with data on UK firms' patenting activity at the US patenting office. They are found to accord well with observed behavior.

Philippe Aghion

Department of Economics

Harvard University

Littauer Center 309

Cambridge, MA 02138

and NBER

p_aghion@harvard.edu

Nicholas Bloom and Rachel Griffith

Institute for Fiscal Studies

nbloom@ifs.org.uk

rgriffith@ifs.org.uk
Peter Howitt

Department of Economics

Brown University, Box B

Providence, RI 02912

and NBER

peter_howitt@brown.edu

Richard Blundell

University College London

r.blundell@ucl.ac.uk 


\section{Introduction}

Economists have long been interested in the relationship between product market competition (PMC) and innovation. Both the theoretical IO and the more recent endogenous growth literatures tackle the issue. Standard IO theory ${ }^{1}$ predicts that innovation should decline with competition, as more competition reduces the monopoly rents that reward successful innovators. However, empirical work such as Geroski (1995), Nickell (1996) and Blundell, Griffith and Van Reenen (1999) has pointed to a positive correlation between product market competition and innovative output. Several theoretical approaches have been used in an attempt to reconcile the Schumpeterian paradigm with the evidence provided in these studies, generating various predictions as to the shape of the relationship between PMC and innovation. ${ }^{2}$

One such approach, introduced by Aghion-Harris-Vickers (1997) and subsequently analyzed in Aghion-Harris-Howitt-Vickers (2001), extends the basic Schumpeterian model by allowing incumbent firms to innovate. In these models, innovation incentives depend not so much upon post-innovation rents per se, but more upon the difference between post-innovation and pre-innovation rents (the latter were equal to zero in the basic model where all innovations were made by outsiders). In this case, more PMC may end up fostering innovations and growth as it may reduce a firm's pre-innovation rents by more than it reduces its

\footnotetext{
${ }^{1}$ See, inter alia, Dasgupta-Stiglitz (1980) and also the first generation of Schumpeterian growth models (Aghion-Howitt (1992), Caballero-Jaffe (1993).

${ }^{2}$ For example, Aghion-Dewatripont-Rey (1999). See Aghion-Howitt (1998), Chapter 7, for a survey of some of these these attempts.
} 
post-innovation rents. In other words, competition may increase the incremental profits from innovating, and thereby encourage R\&D investments aimed at "escaping competition"; and it will do so to a larger extent in more "neck-and-neck" industries, that is in industries in which oligopolistic firms face more similar production costs; the firm with lower (resp. higher) unit costs is referred to as the technological leader (resp. follower) in the corresponding industry, and when both firms have the same unit costs they are referred to as neck-and-neck firms.

In this framework firms innovate in order to reduce production costs, and they do it "step-by-step", in the sense that a laggard firm in any industry must first catch up with the technological leader before becoming itself a leader in the future. In neck-and-neck industries competition is particularly intense and it is also in those industries that the "escape-competition" effect pointed out above is strongest. On the other hand, in less neck-and-neck, or more "unleveled", industries, more competition may also reduce innovation as the laggard's reward to catching up with the technological leader may fall (this is a "Schumpeterian effect" of the kind emphasized in the earlier models). Finally, by increasing innovation incentives relatively more in neck-and-neck industries than in unleveled industries, an increase in product market competition will tend to reduce the fraction of neck-and-neck industries in the economy; this "composition effect" reinforces the Schumpeterian effect in inducing a negative correlation between PMC and aggregate productivity growth or the aggregate rate of innovations.

The paper begins with the derivation of four key empirical predictions of this "step-by-step innovation" model. The first prediction is that the relationship be- 
tween PMC and innovation is an inverted- $U$ shape: that is, the escape-competition effect tends to dominate for low initial levels of competition, whereas the Schumpeterian effect tends to dominate at higher levels of PMC. This prediction is in line with earlier findings of Scherer (1967), Levin, Cohen and Mowery (1985) and others. ${ }^{3}$ The second prediction is that the equilibrium degree of neck-and-neckness should decrease with PMC, as more PMC will increase innovation incentives comparatively more in neck-and-neck sectors, thereby reducing the expected time interval during which an industry remains "neck-and-neck". Third, the higher the average degree of neck-and-neckness of an economy, the stronger the escapecompetition effect will be on average and therefore the steeper the positive part of the inverted-U relationship between PMC and innovation. Fourth, this model predicts that the escape-competition effect should also be stronger in industries where firms' managers face harder budget constraints. As a result, firms with higher debt/cash-flow ratios may innovate more for any level of PMC.

These predictions are confronted with data from a panel of UK firms. We argue that the changes in product market competition and the extensive level of patenting across industries over the last thirty years in the UK make it a particularly interesting environment to assess these predictions. These predictions are examined across a range of industries drawn from a firm panel for the UK. The data are on UK listed firms over the period 1968-1997 and include information on costs, sales, investments and the number of successful patent applications at the US patent office. Detailed information on citations are used to weight our

\footnotetext{
${ }^{3}$ See Cohen and Levin (1989, p.1075) for a brief discussion of this ealier literature.
} 
measure of patents granted for each firm in each year.

A sequence of competition policy reforms, that differ in their impact across industries, are used to argue that the Lerner index we adopt provides a reliable measure of changes in product market competition over the period under study. These policy reforms are further used as instruments to control for the potential endogeneity in the competition index. To capture the degree of neck-and-neckness within each industry we construct a measure of the size of technology gap based on the dispersion of firm level technology and cost indicators. We have matched information at the industry level from the US and other OECD countries which we use to provide further exogenous instruments for the technological gap between leaders and followers across industries. Finally, the long time series on firms in each industry allow us to control for industry level effects as well as common time effects that plague cross-section and time series analyses of these relationships.

The theoretical discussion provides a specification for the average arrival rate of innovations in an industry according to the level of product market competition and the degree of neck-and-neckness. Our empirical specification considers a model for the hazard rate for patenting and uses this to derive a generalized Poisson model for the citation weighted count of patents, which is our main measure of innovative activity. Since we are interested in investigating whether there is a non-monotonic relationship between innovation and product market competition we adopt a semiparametric approach and begin our analysis using a hazard rate specification which is an exponential polynomial spline function in our competition measure. To allow for endogeneity in the measure of product market 
competition we include individual effects and use variation in competition policy across industries. Thus our identifying variation comes from differential changes in competition across industries over time.

A striking finding is of a strong inverted U relationship. We find an exponential quadratic model fits the data extremely well once industry and time effects are allowed for. This single peaked relationship is robust to many alternative specifications and to the endogeneity of the competition index. Controlling for endogeneity and including time and industry effects shifts the peak toward the competitive direction but still suggests the importance of the Schumpeterian effect for a significant minority of firms and industries. This inverted U relationship continues to hold when we split by the degree of neck-and-neckness and when we consider the impact of debt pressure. It is robust to controlling for firm size and for fixed capital costs. The relationship is also found in the data for many individual industries.

The rest of the paper is structured as follows. Section 2 lays out the basic theoretical framework. Section 3 derives our main predictions analytically in the special case of a maximum technological gap equal to one. Section 4 simulates the general model with unbounded gaps and concludes the theoretical part by summarizing our key empirical predictions. Section 5 provides a description of the data and assesses the degree to which the variables used are likely to provide good measures of their theoretical counterparts developed in the earlier sections of the paper. In section 6 we present our main empirical findings. We find a strong accordance between the main theoretical predictions and the empirical results. 
Section 7 provides a short summary and concludes with directions for further research.

\section{A theoretical framework}

\subsection{Consumers}

Suppose that the representative consumer has a utility function of the form:

$$
u=\int_{0}^{1} \ln x_{j} d j,
$$

where each $x_{j}$ is an aggregate of two goods produced by duopolists in sector $j,{ }^{4}$ defined by the subutility function:

$$
x_{j}=v\left(x_{A j}, x_{B j}\right)
$$

where $v$ is homogeneous of degree one and symmetric in its two arguments. We are particularly interested in the special case:

$$
x_{j}=\left(x_{A j}^{\alpha_{j}}+x_{B j}^{\alpha_{j}}\right)^{\frac{1}{\alpha_{j}}}
$$

where a higher $\alpha_{j} \in(0,1]$ reflects a higher degree of substitutability between the two goods in industry $j$.

The log-preference assumption made in (2.1) implies that in equilibrium individuals spend the same amount on each basket $x_{j}$. We normalize this common amount to unity by using expenditure as the numeraire for the prices $p_{A j}$ and $p_{B j}$ at each date. Thus the representative household chooses each $x_{A j}$ and $x_{B j}$ to maximize $v\left(x_{A j}, x_{B j}\right)$ subject to the budget constraint: $p_{A j} x_{A j}+p_{B j} x_{B j}=1$.

\footnotetext{
${ }^{4}$ See Aghion-Howitt (2001) for variants of this model with $N$ firm- industries and free entry.
} 
In the special case where $v\left(x_{A j}, x_{B j}\right)=\left(x_{A j}^{\alpha_{j}}+x_{B j}^{\alpha_{j}}\right)^{\frac{1}{\alpha_{j}}}$, the demand functions facing the two firms in industry $i$ are:

$$
x_{A j}=\frac{p_{A j}^{\frac{1}{a_{j}-1}}}{p_{A j}^{\frac{\alpha_{j}}{a_{j}-1}}+p_{B j}^{\frac{\alpha_{j}}{a_{j}-1}}} \text { and } x_{B j}=\frac{p_{B j}^{\frac{1}{a_{j}-1}}}{p_{A j}^{\frac{\alpha_{j}}{a_{j}-1}}+p_{B j}^{\frac{\alpha_{j}}{a_{j}-1}}} \text {. }
$$

For simplicity we suppress the notation for the industry index $j$ from here on.

\subsection{Technology levels, $R \& D$ and innovations}

Each firm produces using labor as the only input, according to a constant-returns production function, and takes the wage rate as given. Thus the unit costs of production $c_{A}$ and $c_{B}$ of the two firms in an industry are independent of the quantities produced. Now, let $k$ denote the technology level of duopoly firm $i$ in some industry $j$; that is, one unit of labor currently employed by firm $i$ generates an output flow equal to:

$$
A_{i}=\gamma^{k_{i}}, \quad i=A, B
$$

where $\gamma>1$ is a parameter that measures the size of a leading-edge innovation; (equivalently, it takes $\gamma^{-k_{i}}$ units of labor for firm $i$ to produce one unit of output). The state of an industry is then fully characterized by a pair of integers $(l, m)$, where $l$ is the leader's technology and $m$ is the technology gap of the leader over the follower ( $m=0$ when firms are neck and neck). We define $\pi_{m}$ (respectively $\pi_{-m}$ ) to be the equilibrium profit flow of a firm $m$ steps ahead of (respectively behind) its rival. ${ }^{5}$

\footnotetext{
${ }^{5}$ The above logarithmic technology along with the cost structure $c(x)=x \cdot \gamma^{-k}$ implies that the profit in the industry depends only on the gap $m$ between the two firms, and not on absolute levels of technology.
} 
We denote by $\psi(n)=\beta n^{2} / 2$ the $\mathrm{R} \& \mathrm{D}$ cost (in units of labor) of a leader (or neck-and-neck) firm moving one technological step ahead with a Poisson hazard rate of $n^{6}$. We call $n$ the "innovation rate" or "R\&D intensity" of the firm. We assume that a follower firm can move one step ahead with hazard rate $h$ even if it spends nothing on R\&D, by copying the leader's technology. Thus $\beta n^{2} / 2$ is the $\mathrm{R} \& \mathrm{D}$ cost of a follower firm moving ahead with a hazard rate $n+h$. Let $n_{m}$ denote the R\&D intensity of a firm that is $m$ steps ahead of its rival (where $m<0$ in the case of a follower firm).

\subsection{Bellman equations}

Let $V_{m}$ denote the steady state value of being currently a leader (or follower if $m<0)$ in an industry with technology gap $m$, and let $w$ denote the wage rate, which we take as given assuming an infinitely elastic supply of labor. We have the following Bellman equations:

$$
\begin{aligned}
r V_{m} & =\pi_{m}+n_{m}\left(V_{m+1}-V_{m}\right)+\left(n_{-m}+h\right)\left(V_{m-1}-V_{m}\right)-w \beta\left(n_{m}\right)^{2} / 2 ; \\
r V_{-m} & =\pi_{-m}+n_{m}\left(V_{-m-1}-V_{-m}\right)+\left(n_{-m}+h\right)\left(V_{-m+1}-V_{-m}\right)-w \beta\left(n_{-m}\right)^{2} / 2 ; \\
r V_{0} & =\pi_{0}+n_{0}\left(V_{1}-V_{0}\right)+n_{0}\left(V_{-1}-V_{0}\right)-w \beta\left(n_{0}\right)^{2} / 2 .
\end{aligned}
$$

In words, the annuity value $r V_{m}$ of currently being a technological leader in an industry with gap $m$ at date $t$ equals the current profit flow $\pi_{m}$ minus the current

\footnotetext{
${ }^{6}$ Aghion et al (2001) analyze a different model in which the laggard in an industry with technological gap $m$ catches up immediately with the technological leader whenever she innovates, thereby reducing her unit labor cost by $\gamma^{-m}$. This alternative formulation however tends to exaggerate the importance of the escape-competition effect and to downplay the Schumpeterian effect of PMC.
} 
$\mathrm{R} \& \mathrm{D} \operatorname{cost} w \beta\left(n_{m}\right)^{2} / 2$, plus the expected capital gain $n_{m}\left(V_{m+1}-V_{m}\right)$ from making an innovation and thereby moving one further step ahead of the follower, minus the expected capital loss $\left(n_{-m}+h\right)\left(V_{m-1}-V_{m}\right)$ from having the follower catch up by one step with the leader. The equation for the annuity value of a follower is similarly explained. Finally, in the Bellman equation for a neck-and-neck firm, there is no help factor $h$ because there is no leader, and in a symmetric Nash equilibrium both firms' R\&D intensities are equal.

Now, using the fact that each firm chooses its own R\&D intensity to maximize its current value, i.e. to maximize the RHS of the corresponding Bellman equation, we obtain the first order conditions:

$$
\begin{aligned}
\beta w n_{m} & =V_{m+1}-V_{m} \\
\beta w n_{-m} & =V_{-(m-1)}-V_{-m} ; \\
\beta w n_{0} & =V_{1}-V_{0} .
\end{aligned}
$$

\subsection{Product-market competition}

Boone (2000) makes a convincing argument that any parameter increase that would result in increasing the relative profit shares of more advanced firms, that is the profitability of a greater technological lead, would be a suitable measure of product market competition. Thus one possible (inverse) measure of competition ${ }^{7}$ would be the profit flow of neck-and-neck firms, $\pi_{0}$, with a higher $\pi_{0}$ resulting from higher collusion among otherwise similar firms in the same sector.

\footnotetext{
${ }^{7}$ especially in the $m \leq 1$ case analyzed in the next section.
} 
Another potential "measure" of competition from this theoretical standpoint, is the elasticity of substitution parameter $\alpha$ in the case:

$$
v\left(x_{A}, x_{B}\right)=\left(x_{A}^{\alpha}+x_{B}^{\alpha}\right)^{\frac{1}{\alpha}} .
$$

More specifically, assume that in any sector the two duopolists in that sector compete in prices, arriving at a Bertrand equilibrium. According to the demand functions in (2.3), the elasticity of demand faced by each firm $i$ is $\eta_{i}=$ $\left(1-\alpha \lambda_{i}\right) /(1-\alpha)$, where $\lambda_{i}=p_{i} x_{i}$ is the firm's revenue:

$$
\lambda_{i}=\frac{p_{i}^{\frac{\alpha}{\alpha-1}}}{p_{A}^{\frac{\alpha}{\alpha-1}}+p_{B}^{\frac{\alpha}{\alpha-1}}}, i=A, B .
$$

Thus each firm's equilibrium price is:

$$
p_{i}=\frac{\eta_{i}}{\eta_{i}-1} c_{i}=\frac{1-\alpha \lambda_{i}}{\alpha\left(1-\lambda_{i}\right)} c_{i}, i=A, B
$$

and its equilibrium profit is:

$$
\Pi_{i}=\frac{\lambda_{i}}{\eta_{i}}=\frac{\lambda_{i}(1-\alpha)}{1-\alpha \lambda_{i}}, i=A, B .
$$

Equations $(2.5) \sim(2.7)$ can be solved for unique equilibrium revenues, prices and profits. Given the degree of substitutability $\alpha$, the equilibrium profit of each firm $i$ is determined by its relative $\operatorname{cost} z=c_{i} / c_{-i}$; an equiproportional reduction in both $c_{A}$ and $c_{B}$ would induce each firm to reduce its price in the same proportion, which, because industry demand is unit-elastic, would leave the equilibrium revenues and profits unchanged. More formally, $(2.5) \sim(2.7)$ implicitly define a function $\phi(z, \alpha)$ such that:

$$
\Pi_{A}=\phi\left(c_{A} / c_{B}, \alpha\right) \text { and } \Pi_{B}=\phi\left(c_{B} / c_{A}, \alpha\right)
$$


The substitutability parameter $\alpha$ is our measure of the degree of product market competition in each industry. The limiting case of $\alpha=0$ defines the minimal degree of competition; the opposite limiting case of $\alpha=1$ is the case of Bertrand competition between undifferentiated products, which results in perfect competition when the two firms have the same unit cost. Although $\alpha$ is ostensibly a taste parameter, it can be shown to satisfy Boone's requirement. ${ }^{8}$ Furthermore, in this model $\alpha$ corresponds to standard measures of competition. For example, it is a monotonically increasing transformation of the elasticity of substitution in demand $\left(\frac{1}{1-\alpha}\right)$ between the two rivals' outputs in the industry. Given a firm's share $\lambda$ of industry revenue, $\alpha$ is also a monotonically increasing transformation of the elasticity of demand $\frac{1-\alpha \lambda}{1-\alpha}$ faced by the firm. Given a firm's industry share $\lambda, \alpha$ is a monotonically decreasing function of the firm's Lerner index:

$$
L I=\frac{1-\alpha}{1-\alpha \lambda} .
$$

In our empirical analysis, we shall use the Lerner index itself as a measure of PMC, being aware that this index also depends upon the firm's market share $\lambda^{9}$. We also use data on firms' market shares to recover a measure of $\alpha$ for each industry.

\footnotetext{
${ }^{8}$ See Aghion et al (2001) for a formal proof.

${ }^{9}$ The following considerations, suggest that the average Lerner index of a random sample of firms in an industry should be a decreasing function of the $\alpha$ measure of PMC, even after taking into account the effect of $\alpha$ on R\&D intensities and therefore on average market shares. First, for $\lambda$ sufficiently small (which is typically the case in practice), the Lerner index $L I$ is clearly decreasing in $\alpha$; second, we show in the Appendix that for small innovation size $\gamma$ a firm's Lerner is approximately linear in the firm's lead size, so that when averaging across the two firms in the same industry, we approximately get the Lerner index of a neck-and-neck firm (with $\lambda=1 / 2$ ), which itself is decreasing in $\alpha$; third, when we calculate the expected Lerner index of a randomly selected firm under the steady-state distribution of lead size, using the parameters underlying our simulations in section 4 , we again find that the average Lerner index is a decreasing function of $\alpha$.
} 
Both measures are found to produce similar results.

\section{The one-step case}

For expositional simplicity we shall first concentrate on the simple case where knowledge spillovers between leader and follower are such that the maximum sustainable gap is $m=1$. That is, if a firm is one step ahead and it innovates the follower will automatically copy the leader's previous technology and so remain only one step behind. Therefore, given that profitability is only dependent on the gap between leader and follower, no innovation will be undertaken by the leader. At any point in time there will therefore be two types of sectors in the economy: leveled sectors where firms are neck and neck, that is $m=0$, and unleveled sectors where one firm is leading the other in the same industry, with $m=1$.

Assume for simplicity that $w=\beta=1^{10}$, and that there is no help factor for followers $(h=0)$. Using the fact that in this one-step case a technological leader has no incentive to invest in $\mathrm{R} \& \mathrm{D}\left(n_{1}=0\right)$, the above Bellman equations become:

$$
\left.\begin{array}{l}
r V_{1}=\pi_{1}+n_{-1}\left(V_{0}-V_{1}\right) \\
r V_{-1}=\pi_{-1}+n_{-1}\left(V_{0}-V_{-1}\right)-\left(n_{-1}\right)^{2} / 2 \\
r V_{0}=\pi_{0}+n_{0}\left(V_{1}-V_{0}\right)+n_{0}\left(V_{-1}-V_{0}\right)-\left(n_{0}\right)^{2} / 2
\end{array}\right\}
$$

with corresponding first order conditions:

$$
\left.\begin{array}{l}
n_{-1}=V_{0}-V_{-1} \\
n_{0}=V_{1}-V_{0}
\end{array}\right\}
$$

\footnotetext{
${ }^{10}$ We thus take the wage rate as given, with the implicit assumption of an infinitely elastic supply of labor at wage $w=1$. See Aghion et. al (1997) for a discussion of the case where the supply of labor is inelastic.
} 
Thus, for example, the annuity value $r V_{1}$ of being a leader is the current flow of profit $\pi_{1}$ minus the expected capital loss per unit of time from being caught up with by the laggard. The expected loss is the loss in value $V_{1}-V_{0}$ that will occur if the laggard innovates, multiplied by the flow probability $n_{-1}$ of the laggard innovating.

\subsection{Individual innovation intensities}

Equations (3.1) and (3.2) solve for $n_{-1}$ and $n_{0}$. Eliminating the $V$ 's between these equations yields the reduced form $\mathrm{R} \& \mathrm{D}$ equations:

$$
\begin{aligned}
\frac{\left(n_{0}\right)^{2}}{2}+r n_{0}-\left(\pi_{1}-\pi_{0}\right) & =0 \\
\frac{\left(n_{-1}\right)^{2}}{2}+\left(r+n_{0}\right) n_{-1}-\left(\pi_{0}-\pi_{-1}\right)-\frac{\left(n_{0}\right)^{2}}{2} & =0 .
\end{aligned}
$$

This system is recursive, as the first equation solves for $n_{0}$, and then given $n_{0}$ the second equation solves for $n_{-1}$. We obtain:

$$
\begin{aligned}
n_{0} & =-r+\sqrt{r^{2}+2\left(\pi_{1}-\pi_{0}\right)} \\
n_{-1} & =-\left(r+n_{0}\right)+\sqrt{\left(r+n_{0}\right)^{2}+n_{0}^{2}+2\left(\pi_{0}-\pi_{-1}\right)} .
\end{aligned}
$$

Combining (3.5) and (3.6) yields the alternative expression:

$$
n_{-1}=-\left(r+n_{0}\right)+\sqrt{r^{2}+\left(n_{0}\right)^{2}+2\left(\pi_{1}-\pi_{-1}\right)} .
$$

Here, we shall focus on the effects of an increase in product market competition as represented by a reduction in $\pi_{0}$ leaving $\pi_{-1}$ and $\pi_{1}$ unchanged. (The analysis and results in the remaining part of this section can be replicated using the elasticity parameter $\alpha$ as an alternative way to parametrize PMC). We immediately 
see that $n_{0}$ increases whereas $n_{-1}$ can be shown to fall. ${ }^{11}$ The latter effect (on $n_{-1}$ ) is the basic Schumpeterian effect that results from reducing the rents that can be captured by a follower who succeeds in catching-up with its rival by innovating. ${ }^{12}$ The former effect (on $n_{0}$ ) is what we refer to as an "escape-competition effect", namely that more competition induces neck-and-neck firms to innovate in order to escape competition, as the incremental value of getting ahead is increased with higher PMC. Thus, if we were to treat the fractions of leveled and unleveled sectors in the economy as an exogenous parameter, we would get the conclusion that the higher the fraction of neck-and-neck sectors in the economy, the more positive the effect of product market competition on the average innovation rate. This complementarity between PMC and neck-and-neckness will appear more clearly in section 4 below when we simulate the general model with unbounded gaps.

\footnotetext{
${ }^{11}$ From (3.5):

$$
\frac{\partial n_{0}}{\partial \pi_{0}}=-\frac{1}{\sqrt{r^{2}+2\left(\pi_{1}-\pi_{0}\right)}}<0
$$

From this and (3.7):

$$
\frac{\partial n_{-1}}{\partial \pi_{0}}=\frac{\partial n_{0}}{\partial \pi_{0}}\left[-1+\frac{n_{0}}{\sqrt{r^{2}+\left(n_{0}\right)^{2}+2\left(\pi_{1}-\pi_{-1}\right)}}\right]>0
$$

(since $\pi_{1}-\pi_{-1}>0$ ).

${ }^{12}$ As we will see when we allow for $m$ arbitrarily large, this Schumpeterian effect may be counteracted by an "anticipated" escape competition effect. More PMC induces a laggard in a sector with small technological gap (between the leader and that laggard) to increase its $\mathrm{R} \& \mathrm{D}$ investment in order to enter the race for a large technological lead sooner. This and the Schumpeterian effects together give rise to an inverted U-shape relationship between $n_{-m}$ and PMC as measured by $\alpha$ for all $m<0$ (see section 4.2 below).
} 


\subsection{A verage innovation rate}

An increase in product market competition will have an ambiguous effect on the steady-state aggregate innovation rate because it will induce more frequent innovations in currently neck-and-neck sectors and slower innovations in currently unleveled sectors. The overall effect on the average innovation rate and on average productivity growth will depend on the steady-state fraction of time a sector spends being neck-and-neck.

More formally, let $\mu_{1}$ (resp. $\mu_{0}$ ) denote the steady-state probability of being an unleveled (resp. neck-and-neck) industry. During any unit time interval, the steady-state probability that a sector moves from being unleveled to leveled is $\mu_{1} n_{-1}$, and the probability that it moves in the opposite direction is $2 \mu_{0} n_{0}$. In steady state, these two probabilities must be equal:

$$
\mu_{1} n_{-1}=2 \mu_{0} n_{0}
$$

This, together with the fact that:

$$
\mu_{1}+\mu_{0}=1
$$

implies that the average flow of innovations is:

$$
I=\mu_{0} 2 n_{0}+\mu_{1} n_{-1}=2 \mu_{1} n_{-1}=\frac{4 n_{0} n_{-1}}{2 n_{0}+n_{-1}} .
$$

Figure 1 shows a numerical example in which $r=.04, \pi_{-1}=0, \pi_{1}=10$. As $\pi_{0}$ decreases from $\pi=\pi_{1}$, the innovation rate $I$ follows an inverted- $U$ shaped pattern. 


\subsection{The logic of the inverse-U}

The reason for the inverted- $\mathrm{U}$ shape is that when there is not much product market competition, $\pi_{0}$ is close to $\pi_{1}$, so that there is hardly any incentive for firms to innovate when the sector is leveled, and the overall innovation rate will be highest when the sector is unleveled and there is asymmetric competition. Thus the industry will be quick to leave the unleveled state (which it does as soon as the laggard innovates) and slow to leave the leveled state (which won't happen until one of the neck-and-neck firms innovates), and as a result the industry will spend most of the time in the leveled state, where the escape-competition effect dominates $\left(n_{0}\right.$ is decreasing in $\pi_{0}$.) In other words, if the degree of competition is very low to begin with, an increase will result in a faster average innovation rate.

On the other hand, when competition is very high, $\pi_{0}$ is close to $\pi_{-1}$ so there is relatively little incentive for the laggard in an unleveled state to innovate. ${ }^{13}$ Thus the industry will be relatively slow to leave the unleveled state. Meanwhile the large incremental profit $\pi_{1}-\pi_{0}$ gives firms in the leveled state a relatively large incentive to innovate, so that the industry will be relatively quick to leave the leveled state. As a result, the industry will spend most of the time in the unleveled state where the Schumpeterian effect is at work on the laggard, while the leader never innovates. In other words, if the degree of competition is very high to begin with, an increase may result in a slower average innovation rate.

\footnotetext{
${ }^{13}$ Of course there is still an incentive for the laggard to innovate even if $\pi_{0}=\pi_{-1}$, because, although an innovation will not raise current profits, it will take the firm one step closer to possibly attaining a leader's profit $\pi_{1}$.
} 
Hence the possibility of an inverse- $U$ relationship between competition and innovation. When competition is low, an increase will raise innovation through the escape-competition effect, but when it becomes intense enough it may lower innovation through the Schumpeterian effect on laggards. The reason why one effect dominates when competition is low and the other when competition is intense is the "composition effect" on the steady-state distribution of technology gaps.

To see this composition effect more clearly note that in the steady state distribution:

$$
\mu_{0}=\frac{n_{-1}}{n_{-1}+2 n_{0}} \quad \text { and } \quad \mu_{1}=\frac{2 n_{0}}{n_{-1}+2 n_{0}}
$$

In the limit when there is no competition $\left(\pi_{0}=\pi_{1}\right),(3.5)$ implies that $n_{0}=0$, so that in the steady state the industry is always leveled $\left(\mu_{0}=1\right)$, whereas when there is the maximum competition $\left(\pi_{0}=\pi_{-1}\right),(3.5)$ and (3.7) imply that $n_{0}>n_{-1}$, so that the overall rate of innovation in the leveled state is more than twice that in the unleveled state and as a result the fraction of time $\mu_{0}$ spent leveled in steady state is less than $1 / 3$.

In the general model with no upper bound on the technological gap this inverted U will be reinforced by the fact that in an unleveled industry the laggard's individual R\&D intensity will itself be inverse- $U$ shaped. This is because the anticipated escape-competition effect mentioned in footnote 12 on laggards, which is always dominated by the Schumpeterian effect in the one-gap model, is the dominant effect in the general model when competition is low. 


\subsection{Debt pressure and product market competition}

In this subsection we explore the interplay between product market competition and debt pressure indicators such as debt-exposure (and the resulting probability of incurring bankruptcy costs) and the magnitude of default costs (which one could interpret as reflecting the hardness of firms' budget constraints). Clearly, debt pressure can reduce innovation by making $R \& D$ investments hard to finance. However, our model implies that there is also an effect going in the opposite direction, which is similar to the escape-competition effect. Specifically, we show that higher debt pressure and/or higher default costs may induce firms to innovate more in order to escape debt pressure and costly bankruptcy.

To formalize the interplay between competition and the exposure to bankruptcy costs, we consider the following variant of the basic one-step model: (1) neck-and-neck profit flows $\widetilde{\pi}_{0}$ are random, i.i.d. over time and uniformly distributed over the interval $\left[\pi_{0}, \pi_{0}+1\right] ;(2) \pi_{-1} \equiv 0 ; \pi_{1}$ constant with $\pi_{1}>>\pi_{0}+1$; (3) firms finance their investments through debt financing, which we define here as involving a fixed flow repayment obligation $D$, and a default cost $f$ incurred per period of time by the firm whenever its profit falls below $D .{ }^{14}$

Consider first the case where exit costs are negligible and where $D \in\left(\pi_{0}, \pi_{0}+\right.$ 1); then, the Bellman equations for equilibrium R\&D investments, can be ex-

\footnotetext{
${ }^{14}$ This formulation is inspired from the costly state verification literature (e.g Townsend (1979), Gale-Hellwig (1985)) on debt-financing, in which firms' revenues are assumed to be unverifiable by outside investors, unless they incur a flow verification cost $f$. For simplicity, we abstract in this section from firms' choice over the optimal financial contract.
} 
pressed as:

$$
\begin{aligned}
r V_{1} & =\pi_{1}-D+n_{-1}\left(V_{0}-V_{1}\right) \\
r V_{0} & =\psi\left(\pi_{0}, D, f\right)+n_{0}\left(V_{1}-V_{0}\right)+n_{0}\left(V_{-1}-V_{0}\right)-n_{0}^{2} / 2 \\
r V_{-1} & =-f+n_{-1}\left(V_{0}-V_{-1}\right)-\left(n_{-1}\right)^{2} / 2 .
\end{aligned}
$$

where

$$
\psi\left(\pi_{0}, D, f\right)=\int_{D}^{\pi_{0}+1}(u-D) d u-f \int_{\pi_{0}}^{D} d u
$$

is the expected flow utility of a manager in a new industry, net of the expected verification costs. From these Bellman equations and the corresponding first order conditions, we obtain the following expression for the equilibrium neck-and-neck firm's innovation rate:

$$
n_{0}=-r+\sqrt{r^{2}+2\left(\pi_{1}-D-\psi\right)}=-r+\sqrt{\delta},
$$

where we re-express $\psi$ as:

$$
\psi=\frac{1}{2}\left(\pi_{0}+1-D\right)^{2}-f\left(D-\pi_{0}\right)
$$

Hence:

$$
\frac{\partial n_{0}}{\partial \pi_{0}}=-\left(\pi_{0}+1-D+f\right) / \sqrt{\delta}<0
$$

Suppose first that the default cost $f$ is constant. Then, provided $f$ is large enough we find that the effect of increasing the firm's leverage $D$, will be to raise innovation. That is:

$$
\frac{\partial n_{0}}{\partial D}=\left(\pi_{0}-D+f\right) / \sqrt{\delta}
$$


which is positive if $f>D-\pi_{0}$. Thus, for any level of PMC, higher debt pressure as measured by a higher level of $D$ will result in more $R \& D$ by neck and neck firms.

Consider next the effect of an increase in the default cost $f$, which we interpret as a hardening of the firm's budget constraint. We immediately have:

$$
\frac{\partial n_{0}}{\partial f}>0
$$

that is, a higher cost of default induces firms to innovate more in order to escape the threat of bankruptcy.

\section{The general model}

In principle, one can solve the general model, but closed form solutions are hard to derive when $m$ is large, and the best one can do is to solve it numerically. We use the parameter values $r=0.1, \gamma=1.75, w=1, \beta=15, h=0.025$. Figure 2 shows how the value $V_{m}$ of a firm depends on $m$ and on $\alpha$, which we now use to parametrize PMC. The larger $\alpha$, that is the higher the degree of PMC, the higher the curvature of the logistic $V_{m}$ as a function of $m$ in the neighborhood of $m=0$.

\subsection{Industry innovation rate}

Using the same equations, we can also characterize the relationship between $\alpha$ and the individual R\&D intensities $n_{m}$ and $n_{-m}$. Figure 3 depicts the relationship between $\alpha$ and total intra-industry R\&D intensity $\left(n_{m}+n_{-m}\right)$. We see an inverted$\mathrm{U}$ shaped pattern for $m \neq 0$, which in turn results from the interplay between the 
escape-competition and Schumpeterian effects of PMC on innovation incentives. We also see that innovation intensities are higher and also increase more rapidly with $\alpha$ in the case of neck-and-neck firms. Thus, there is complementarity between PMC and the degree of neck-and-neckness as measured by how small $m$ is. The relationship between PMC and innovation becomes increasingly steeper as $m$ goes down, i.e. as the industry becomes more neck-and-neck.

\subsection{Industry structure and steady-state innovation/growth rates}

In the equilibrium we define $\mu_{m}$ to be the steady state fraction of time the industry spends with technological gap $m$. We obviously have:

$$
\sum_{m} \mu_{m}=1
$$

In addition, the following equations must also hold in steady-state:

$$
\mu_{m}\left(n_{m}+n_{-m}+h\right)=\mu_{m-1} n_{m-1}+\mu_{m+1}\left(n_{-(m+1)}+h\right)
$$

for all $m \geq 2$. The LHS of this equation represents the flow probability of exiting technological gap (or "state") $m$; the RHS represents the flow probability of entering state $m$, both, from state $(m-1)$ with the leader innovating, and from state $(m+1)$ sectors with the follower innovating. For $m=1$ we have:

$$
\mu_{1}\left(n_{1}+n_{-1}+h\right)=2 \mu_{0} n_{0}+\mu_{2}\left(n_{-2}+h\right)
$$

as two firms instead of one can turn a neck-and-neck sector into an unleveled sector with technological gap $m=1$. 
And for $m=0$, we simply have:

$$
2 \mu_{0} n_{0}=\mu_{1}\left(n_{-1}+h\right) .
$$

In other words, a neck-and-neck sector becomes unleveled whenever a firm in that sector innovates, and only state-1 sectors can become neck-and-neck whenever the laggard in that sector innovates. Figure 4 depicts $\mu$ as a function of $m$ and $\alpha$. We see that on average the industry becomes increasingly neck and neck as P MC decreases.

Now, we can compute the average rate of productivity growth for the industry. In the general case where the lead size $m$ can take any integer value, one can show that the average growth rate of the industry is equal to:

$$
g=\left(2 \mu_{0} n_{0}+\sum_{k \geq 1} \mu_{k} n_{k}\right) \ln \gamma
$$

Equation $(\mathrm{G})$ states that the growth rate equals the product of the frequency of "frontier innovations" (innovations by the industry leader or a neck-and-neck firm, which advance the industry's frontier technology) and the (log) size of innovations. Figure 5 depicts $g$ as a function of $\alpha$. We again obtain an inverted $U$-shape.

\subsection{The key theoretical predictions}

We conclude the theoretical part of the paper by stating four main predictions that came out of our analysis in the previous sections, and which we test in the empirical part of the paper:

1. The relationship between product market competition and the average innovation rate is an inverted- $U$ shape. 
2. The expected technological gap in an industry increases as product market competition increases, that is the distribution shifts towards a lower probability of being neck-and-neck.

3. There is a complementarity between product market competition and the degree of neck-and-neckness of an industry. The closer firms are in technology space (the more neck-and-neck firms are in that industry) the steeper the positive effect of product market competition on innovation and the larger the average number of innovations.

4. Firms with higher debt/cash-flow ratios may innovate more for any level of PMC.

\section{Data and Measurement I ssues}

The empirical investigation is based on a panel of individual UK companies covering the period 1968-1997. The UK over this period provides an extremely rich environment within which to study the impact of product market competition on

innovation behavior. Not only is there a long panel of detailed company data, but this period also saw a number of significant, and largely exogenous, changes in product market competition. These changes, which altered the structure of product market competition across industries, included the implementation of the European Single Market Program, a series of structural and behavioral reforms imposed on different industries as a result of investigations by the Monopolies and Mergers Commission (MMC) under the Fair Trading Act and large scale privati- 
zations. We document these in more detail below and argue that they provide a powerful set of instrumental variables for our measure of competitiveness.

There are two main data sources used in this study - firm level accounting data and administrative data from the US patents office. ${ }^{15}$ These allow us to combine information on technological performance, revenues, labor costs and capital costs. The accounting data come from Datastream and include all firms quoted on the London Stock Exchange between 1968 and 1997. ${ }^{16}$ The patenting information on each firm is drawn from the US Patent Office. This dataset in turn was matched to a subset of the firms for which accounting data is available. We have patents data for all firms with a name beginning A-L (plus all large R\&D firms) that were listed on the London Stock Exchange any time between 1983 and 1985. These have been matched to all of their subsidiaries in $1985 .{ }^{17}$ This data runs from 1968-1997 and contains 461 firms with 236 firms that patent. We do not use the first three years or the last three years of data in estimation, although we do use them to construct the citation weighting.

In order to test the predictions detailed in section 4 we need measures of firms' innovative output, the degree of product market competition in an industry, the size of the technology gap between firms within an industry (how "neck-and-neck"

\footnotetext{
${ }^{15}$ This data was developed with funding from the Leverhulme Trust. See Bloom and Van Reenen (2000) for a more detailed description of the data.

${ }^{16}$ We removed firms with missing values on sales, capital or employment, firms with less than three consecutive observations, observations for firms with abnormal length accounting periods (we drop firms whose accounting period falls outside 300 to 450 days due to changes in accounting year ends) and exclude observations for firms where there was a jump of greater than $150 \%$ in any of the key variables (capital, labour, sales).

${ }^{17}$ This matching has been done by hand in order to achieve a higher match rate than with computer matching.
} 
firms are) and the extent of bankruptcy threat facing each firm. We discuss each of these in turn.

\subsection{M easuring innovation}

There is a large literature on measuring innovation intensity. The most commonly used measures at the firm level are research and development spending, patenting activity, innovation counts and total factor productivity. Although R\&D expenditure is available in the UK, and we use it to check the robustness of our results, it is not mandatory for firms to report it, and prior to 1990 it is frequently not reported. We do not use total factor productivity (TFP) as a measure of innovative activity because of the well known problem that commonly used measures of TFP are themselves biased in the presence of imperfectly competitive product markets. ${ }^{18}$ For these reasons our main measure of innovation is based on information on patents taken out by UK firms in the US patent office. Our data includes information on all patents taken out by the $461 \mathrm{UK}$ stock market listed firms. ${ }^{19}$

The US patenting office is where innovations are patented internationally. These patents can be based on research conducted anywhere in the world. In our dataset about $54 \%$ of the patents take out by UK firms in the US were invented by someone working outside of the US. We also have information on citations to and from these patents. One concern that is often expressed about using patent counts is that patents may not be comparable across firms or industries

\footnotetext{
${ }^{18}$ See, inter alia, Hall (1988), Klette and Griliches (1996) and Klette (1999).

${ }^{19} \mathrm{As}$ we highlight below, the complete set of UK stock market firms is used to construct the other industry measures we require.
} 
because their value can vary significantly. Therefore, we use the number of times a patent has been cited in other patents to weight the patent, and thus provide a measure that is more indicative of the value of the patent. ${ }^{20}$ We can extend the interpretation of our results for patents to productivity growth, as patents are well known to have a strong effect on productivity growth. ${ }^{21}$ This has been demonstrated directly for our dataset by Bloom and Van Reenen (2000) who find a highly significant response of productivity to both patents and patent citations. Figure 6 presents a frequency histogram of annual firms level patent count. This picture excludes the $37 \%$ of observations with zero patents. It also truncates the distribution at 50 patents per year per firm. As we note below, there are a few very large patenting firms in our data.

\subsection{M easuring the degree of product market competition}

As discussed in section 2.4, our main indicator of product market competition is the Lerner Index or price cost margin. This measure has several advantages over indicators such as market shares or a Herfindahl or concentration index. In order to measure any of those it is necessary to have a definition of both the geographic and product boundaries of the market in which the firm operates. This is particularly important in our application as many innovative UK firms operate in international markets, so that traditional market concentration measures could

\footnotetext{
${ }^{20} \mathrm{Hall}$, Jaffe and Trajtenberg et al. (2001) use the US Patent Office patenting data set to examine the effects of patenting on the market value of US firms.

${ }^{21}$ See for example the survey of the patenting literature in Griliches (1990).
} 
be extremely misleading. ${ }^{22}$

We use information reported in Datastream, which we have for all UK stock market listed firms. Accounting data is used to construct a firm level measure similar to Nickell (1996)'s measure of rents over value-added. The Lerner Index is price minus marginal cost over price. One difficulty we face is that we do not observe marginal cost. For the numerator we use operating profits net of depreciation and provisions. We deduct an estimate of the financial cost of capital (cost of capital* ${ }^{*}$ capital stock) from our measure of profits. ${ }^{23}$ This is more like price minus average cost. We divided this by sales.

$$
l i_{i t}=\frac{\text { operating profit }- \text { financial cost }}{\text { sales }}
$$

At the firm level the Lerner Index varies from 0 to 0.38 , has a mean of 0.09 and a median value of $0.08 .^{24}$

In our econometric analysis below we present results with this individual firm level index. However, we also find that our results are robust to using the industry level aggregate. This robustness to the use of the industry level product

\footnotetext{
${ }^{22}$ One example of the difficulties in using concentration indexes is provided by the pharmaceutical industry, which account for about $10 \%$ of global R\&D. In the UK the pharmaceutical industry is dominated by two large players, GlaxoSmithKline and AstraZeneca, whose sales accounts for about $65 \%$ and $30 \%$ of the market. But these firms are global players, competing with other US and European firms. In global terms they have market shares of $7 \%$ and $4 \%$; these low market shares in turn reflect the fierce competition in the industry. In this case, without global market sales, concentration measures would be extremely misleading.

${ }^{23}$ Where the cost of capital is assumed to be 0.085 for all firms and time periods and capital stock is measured using the perpetual inventory method.

${ }^{24}$ In UK accounts capital depreciation, R\&D expenditure and advertising have been deducted. In theory we would like to deduct R\&D depreciation (rather than expenditure), but this is not available and we note that in steady state investment in the $R \& D$ stock should equal depreciation.
} 
competition measure is important since it is the industry level variation in the policy instruments which we exploit to purge the endogeneity in the competition measure. Consequently for our central specification we relate firm level innovation activity to the industry level competition index. Identification will come from variation across industries over time. The industry level index, denoted $c_{j t}$, is an unweighted average across all firms in the industry,

$$
c_{j t}=1-\frac{1}{N_{j t}} \sum_{i \in j} l i_{i t}
$$

where $i$ indexes firms, $j$ indexes industry, $t$ indexes time and $N_{j t}$ is the number of firms in industry $j$ in year $t$. A value of 1 indicates perfect competition (price equals marginal cost) while values below 1 indicate some degree of market power. In computing this index we use the entire sample of Datastream firms, not just those in the patenting sub-sample. Firms in our data can operate in many industries. We classify firms by the 2-digit SIC code in which the firm had the largest proportion of its sales in 1995. For $33 \%$ of the firms this represented all of their sales. The median share of sales accounted for by the largest industry is $90 \%{ }^{25}$

As an alternative competition measure we derive an estimate of the industry substitution parameter $\alpha$ as described in (2.9). First we remove the effect of market share on a firm's profit-margin,

$$
A_{i t}=\frac{1-l i_{i t}}{1-m s_{i t} * l i_{i t}}
$$

\footnotetext{
${ }^{25}$ For firms operating in more than one market the Lerner Index will represent a weighted average of the degree of product market competition across these markets. This could lead to measurement error and attenuation bias. We discuss this further in the empirical section below.
} 
The market share is measured as the firm's share of output produced by firms in the same 2-digit industry on the London Stock Market. As above, an unweighted average across firms within a 2-digit industry is taken

$$
\alpha_{j t}=1-\frac{1}{N_{j t}} \sum_{i \in j} A_{i t} .
$$

This alternative measure inherits the concerns about measuring market shares of firms operating in international markets, as discussed above (footnote 22). But it provides one way to assess the robustness of our empirical results. Figure 7 presents the time path of the Lerner index and our estimate of $\alpha_{j t}$ for six of the manufacturing industries used in the study. ${ }^{26}$ This shows a wide variation in the index over time that differs systematically across industries.

\subsection{The Policy Instruments}

One of our main concerns is that the competition measure may be endogenous to the patenting decision. We address this problem in a sequence of steps. First, we allow for industry effects thus removing bias that results from correlation between permanent levels of innovative activity and product market competition. Second, we use a set of 'policy' instruments that provide exogenous variation in the degree of industry wide competition. Since we are including industry and time effects this approach identifies the competition effect through differential changes across industries in the policy instruments.

We use three types of policy instruments - the EU Single Market Programme,

\footnotetext{
${ }^{26}$ Extraction of other minerals (23), Chemical industry (25), Manufacture of office machinery (33), Electrical and electronic (34), Motor vehicles and parts (35), Food (41).
} 
Monopoly and Merger Commission investigations that resulted in structural or behavior remedies being imposed on the industry, and major privatizations. The table below lists the SIC codes and also the years in which the various policies were implemented:

\begin{tabular}{|l|l|l|}
\hline Policy instruments & & \\
\hline & SI C & Y ears \\
\hline SMP high & see appendix & 1988 \\
\hline SMP medium & see appendix & 1988 \\
\hline Cars & 351 & $1984,1987,1988$ \\
\hline Car Parts & 353 & 1982,1987 \\
\hline Periodicals & 475 & 1987 \\
\hline Brewing & 427 & 1986 \\
\hline Telecoms & 344 & $1981,1984,1989$ \\
\hline Textiles & 430 & 1989 \\
\hline Razors and Razor blades & 316 & 1990 \\
\hline Steel & 220 & 1987 \\
\hline Ordnance & 329 & 1987 \\
\hline
\end{tabular}

Appendix B provides more detail on the policies and the industries that were affected.

\subsection{Technology gap}

To assess the second and third theoretical predictions a measure of the size of the technology gap between firms within an industry is required. We capture this gap by the proportional distance a firm is from the technological frontier, as measured by total factor productivity. More formally, we let:

$$
m_{i t}=\frac{T F P_{F t}-T F P_{i t}}{T F P_{F t}}
$$


where $F$ denotes the frontier firm (with the highest TFP) and $i$ denotes nonfrontier firms. For the frontier firm our measure is

$$
m_{F t}=\frac{T F P_{F t}-T F P_{F-1 t}}{T F P_{F t}},
$$

where $F-1$ denotes the firm just behind the frontier. In the empirical application below we use an industry level measure that is the average across firms in the industry

$$
m_{j t}^{t f p}=\frac{1}{N_{j t}} \sum_{i \in j} m_{i t}
$$

where $N_{j t}$ is the number firms in industry $j$ at time $t$. We measure this using data on all UK stock market listed firms. A lower value of $m_{j}$ indicates that firms in industry $j$ are technologically closer to the frontier (and therefore more like the neck and neck firms in our theoretical section) while a high value of $m_{j}$ indicated a large technological gap with the frontier (so that firms in that industry are more like laggard firms in an unleveled industry).

\subsection{Summary Statistics}

Table 1 shows the number and proportion of observations where we have both accounting and patents data and where we have only accounting data. On average patents data are observed for $34 \%$ of the complete Datastream sample. Industries are excluded where we have fewer than three firms or where there were no patents throughout the period 1968-1997. Our sample contains 330 firms with 4,500 observations over the period 1971-1994 in seventeen 2-digit industries. Of these there are 236 patenting firms, with around 60,000 patents in total which 
account for around 200,000 citations.

Table 2 shows the average of the firm level Lerner Index for the sample of firms where we have only accounting data and for the sample where we have both accounting and patents data. The table shows that the firms we have in our sample are similar in terms of their Lerner Index to those not in our sample - both are used to construct our industry measure of the Lerner. At the industry level the Lerner averages $4 \%$ and ranges from $13 \%$ in Office \& Computing Machinery in 1973 to less than 1\% in Motor Vehicles in 1982.

Table 3 presents the descriptive statistics on our sample of 330 firms. From this we can see that the patent count is highly skewed, with most firms taking out no patent in any given year, but one firm (ICI in 1974) taking out 409 patents. The employment figures reflect firm size, with about 1,500 employees in the median firm.

The measure of the technology gap also has a large spread, ranging from industries in which leader and follower firms all have very similar levels of TFP (those with measures close to 0), to industries in which the leader is far ahead of the rest of the industry (those with measures close to 1 ).

The financial pressure variable is debt payments over operating profits plus depreciation. This also shows a similarly large spread between firms in which debt repayments consume all their cash flow (a pressure measure of 1) to those with little or no debt (a pressure variable of 0 ). 


\section{Empirical Support for the Inverted U}

Earlier analysis using UK company data ${ }^{27}$ established that indicators of the level of competition, both at the firm and industry level, had significant and largely positive impacts on innovation intensity at the firm level. The aim here is to take this research forward by assessing the four key predictions derived in our theoretical discussion: (i) an inverted U-shaped relationship between product market competition and the average innovation rate; (ii) an increase in the average technological gap as product market competition increases; (iii) complementarity between product market competition and the degree of neck-and-neckness of an industry; (iv) a higher rate of innovation for firms with higher debt/cash-flow ratios for any level of PMC.

\subsection{A M ethod of M oments Estimator}

The central relationship we estimate is that between product market competition and the innovation rate. Denoting $n$ as the hazard rate and $c$ as the measure of competition, we express this as

$$
n=e^{g(c)} .
$$

Suppose the patent process has a Poisson distribution with hazard rate (6.1). The resulting count of patents in any time interval has the probability distribution

$$
\operatorname{Pr}[p=k \mid c]=e^{g(c) k} e^{-e^{g(c)}} / k !
$$

\footnotetext{
${ }^{27}$ See, inter alia, Nickell (1996), Geroski (1995), Blundell, Griffith and Van Reenen (1995,1999).
} 
and the expected number of patents satisfies

$$
E[p \mid c]=e^{g(c)}
$$

Parametric models that study count data processes typically base their specification on this Poisson model with a parametric (linear) form for $g(c)$, but they relax the strong assumptions on higher moments implicit in (6.2) ${ }^{28}$ We base our estimator on the first moment (6.3). The Poisson MLE is a consistent estimator in this case but overdispersion, common in innovation and patent data sets, implies that the estimated variance covariance matrix is incorrect. We follow this approach in our empirical analysis but, because we are particularly interested in allowing the data to determine the shape of the relationship between innovation and product market competition, we adopt a flexible specification for $g(c)$.

In our data firms $i=1, \ldots . N_{t}$ are grouped into $J$ mutually exclusive industries with $i \in I_{j}$ with $j=1, \ldots, J$. We observe firms for $t=1, \ldots, T_{i}$ periods. Our principle competition measure (5.1) is aggregated to the industry level while patents are measured for each firm. Following from the specification of the conditional mean (6.3) we write

$$
E\left[p_{i t} \mid c_{j t}\right]=e^{g\left(c_{j t}\right)},
$$

where $g(c)$ is nonparametric. This directly identifies the innovation hazard (6.1). Note also that (6.4) is fully nonparametric but will be extended into a semiparametric specification as we introduce more conditioning variables into the mean specification.

\footnotetext{
${ }^{28}$ See Hausman, Hall and Griliches (1984), for example.
} 
It is very likely that firms in different industries will have observed levels of patenting activity that have no direct causal relationship with product market competition but reflect other institutional features of the industry. Consequently industry fixed effects are essential to remove any spurious correlation or 'endogeneity' of this type. Time effects are also included to remove common macroeconomic shocks. Conditional on industry and time, average patent behavior is related to industry competition according to

$$
E\left[p_{i t} \mid c_{j t}, x_{j t}\right]=e^{\left\{g\left(c_{j t}\right)+x_{i t}^{\prime} \beta\right\}},
$$

where $x_{i t}$ represent a complete set of time and industry dummy variables. We use moment condition (6.5) to define a semiparametric moment estimator and approximate $g(c)$ with a polynomial spline function. ${ }^{29}$

\subsection{The Basic Inverted U Relationship}

The estimated exponential spline is presented in Figure 8. It shows a strong inverted $U$ relationship between innovation, as measured by the citation weighted patent count, and product market competition. The smoother curve in Figure 8 replaces the exponential spline function with an exponential quadratic. The dotted lines are $95 \%$ confidence bands. The estimated coefficients for the exponential quadratic model are presented in the first column of results in Table 4a. It is interesting to note that the exponential quadratic specification provides a very reasonable approximation and retains the clear inverted U. The underlying

\footnotetext{
${ }^{29}$ See Ai and Chen (2001).
} 
distribution of the data is shown by the intensity of the points on the estimated curves. These indicate that the peak of the inverted U lies near the median of the distribution (the median is 0.95 ). We can also see that a simple linear relationship would yield a positive slope; this confirms the results presented in Nickell (1996) which documents the positive (linear) impact of industry level competition on innovation in a model using firm level UK data. Finally one can show that the inclusion of industry and time effects makes the competition effect on innovation more pronounced than when they are not included..$^{30}$

One immediate question relates to aggregation of the competition measure to the 2-digit level. Our main argument for working at the industry level for the competition measure is that we observe instruments that have industry level variation in competition policy and thus which allow us to purge the product market variable of endogeneity. The results using these instruments are presented below. Before doing this we show that the relationship also holds at the most disaggregated level. Figure 9 presents the exponential quadratic level model estimated using firm level competition measures. The similarity with Figure 8 is striking. The inverted $U$ relationship appears to be robust to the 2-digit industry level aggregation of the competition measure. This inverted U relationship is also preserved when we consider firms in different industries separately. Figure 10 presents the relationship fitted separately for each of the top four innovating industries in our sample. In each case there is an inverted $U$ shape.

Before moving to the results using the policy instruments we perform two

\footnotetext{
${ }^{30}$ The corresponding results are available from the authors.
} 
further robustness checks. The first considers the alternative product market competition measure $\alpha$ as defined in (5.2). The results are presented in Figure 11 and again the overall inverted $U$ relationship remains in place. ${ }^{31}$ The second uses $\mathrm{R} \& \mathrm{D}$ expenditure as an alternative innovation measure. Above we noted that in the UK R\&D expenditure was not widely reported in firms' accounts before 1990 . Nonetheless we use it as a robustness check. We have 1,162 observations from 1980 - 1994 where R\&D is reported. In 1980 only six firms in our data reported R\&D. From 1990 over 150 firms report R\&D. We estimate a model of the form

$$
\ln (R \& D)_{i t}=g\left(c_{j t}\right)+x_{i t}^{\prime} \beta+u_{i t}
$$

Figure 12 plots the $g\left(c_{j t}\right)$ function as above, and shows that the inverted U result is preserved.

\subsection{Endogeneity}

The inclusion of industry and time dummies may not be sufficient to remove all spurious correlation between the competition measure and the patent count. In particular, relative changes in the competition measure across industries in the UK may be indirectly caused to some extent by shocks to UK patents. Now, recall that our main measure of product market competition was constructed as an average of the firm level measure using data from firms both within our sample and outside our sample. This already alleviates the endogeneity problems that arise due to time varying, firm specific shocks or measurement errors. However,

\footnotetext{
${ }^{31}$ Using lagged Lerner indexes to measure PMC, turns out to generate a very similar picture.
} 
our main approach to remove such temporal correlations is to use the policy instruments described in section 5.3. We adopt a control function approach. ${ }^{32}$ This differs from standard IV (and GMM) in nonlinear models. The idea is to use functions of the residuals from the regression of the competition index on the instruments as controls in an extended version of the moment condition (6.5).

Without loss of generality we write our underlying stochastic model for patents as

$$
p_{i t}=e^{\left\{g\left(c_{j t}\right)+x_{i t}^{\prime} \beta+u_{i t}\right\}} .
$$

Exogeneity of $c$ and $x$ implies

$$
E\left[e^{u_{i t}} \mid c_{j t}, x_{j t}\right]=1
$$

resulting in the moment condition (6.5). Under endogeneity of $c$ this moment condition on $u_{i t}$ no longer holds. However, let us assume the existence of instruments $z_{i t}$ that obey the reduced form equations:

$$
c_{j t}=\pi\left(z_{j t}\right)+x_{i t}^{\prime} \gamma+v_{j t}
$$

with

$$
E\left[v_{i t} \mid z_{i t}, x_{j t}\right]=0
$$

The control function assumption can then be expressed as:

$$
E\left[e^{u_{i t}} \mid c_{j t}, x_{j t}, v_{i t}\right]=1,
$$

\footnotetext{
${ }^{32}$ See Newey, Powell and Vella (1999).
} 
so that controlling for $v_{i t}$ in the conditional moment condition is sufficient to retrieve the conditional moment assumption. In estimation we use the extended moment condition (6.4)

$$
E\left[p_{i t} \mid c_{j t}, x_{j t}, v_{j t}\right]=e^{\left\{g\left(c_{j t}\right)+x_{i t}^{\prime} \beta+\rho\left(v_{j t}\right)\right\}} .
$$

To recover the parameters of interest we can integrate over the distribution of $v$ and recover the 'average structural function' (see Blundell and Powell (2001)

$$
E\left[p_{i t} \mid c_{j t}, x_{j t}\right]=\int e^{\left\{g\left(c_{j t}\right)+x_{i t}^{\prime} \beta+\rho v_{j t}\right\}} d F_{v}
$$

This is achieved using the empirical distribution for $v$.

The second column in Table $4 \mathrm{a}$ presents the estimates for our exponential quadratic specification that control for endogeneity using our set of instruments. The coefficient estimates are similar to the first column. In the bottom part of the table we present some diagnostic statistics. They show that the instruments are significant in the reduced form, that the policy instruments in particular are significant, and that they have explanatory power. Figure 13 plots the relationship between innovation and product market competition and displays a similar inverted $U$ relationship to that found in our baseline specification. This provides strong evidence in support of our first key prediction.

\subsection{Technological Gap and Product M arket Competition.}

The empirical analysis presented so far has studied the impact of product market competition at the industry level on the level of patenting activity. We now look at the importance of similarities in technology across firms in the same industry - 
defined by the size of the technology gap or the degree of neck-and-neckness. The second key prediction derived from the theoretical discussion is that in equilibrium the average technology gap between leaders and followers should be an increasing function of the overall level of industry wide competition (so that average neckand-neckness should be a decreasing function of competition).

Measuring average technological distance from the frontier by the variable $m$ specified in section 5.4, Figure 14 presents a kernel smoothed plot of $m$ for each industry time observation against the industry competition index. This shows a strongly positive relationship as predicted by the theory. In particular, more competitive industries display a lower degree of neck-and-neckness.

A third theoretical prediction is that the inverted $U$ shaped relationship between competition and growth should be steeper for more neck and neck industries. To assess this prediction, we consider a subsample of our data - firms in industries with below median technological gap - these are more neck and neck industries. Figure 15 presents a picture of the baseline exponential quadratic specification, as well as the same specification estimated on the sample of firms in high neck and neck industries. Two features stand out clearly. First, more neck and neck industries show a higher level of innovation activity for any level of product market competition. ${ }^{33}$ Second, the inverted U curve is steeper for the more neck and neck industries. This accords well with the theoretical simulations presented in section 4. The estimated exponential quadratic specification for the high neck and neck

\footnotetext{
${ }^{33}$ The unconditional mean of citation weighted patents for high neck and neck firms is 8.58, compared to 6.68 for the entire sample.
} 
firms are shown in the first column of Table $4 \mathrm{~b}$.

As a check on these results, and in addition to the full set of time and industry effects, we allow for endogeneity in the neck and neck split, as well as in the degree of competition. The instruments ${ }^{34}$ work well as evidenced by the high $R^{2}$ shown in Table $4 \mathrm{~b}$ and the significance of both the policy instruments and the other instruments. The impact of controlling for the endogeneity of the sample separation between high and low neck and neck industries in the exponential quadratic specification is presented in Table $4 \mathrm{~b}$. The strong quadratic pattern remains, and one can also show that the impact of controlling for endogeneity is to reinforce the escape-competition effect for more neck and neck firms. ${ }^{35}$

\subsection{Financial pressure}

Our fourth and final key prediction is that higher debt pressure should reinforce the escape-competition effect of PMC and thereby enhance innovation incentives especially at lower levels of product market competition. We measure financial pressure using the ratio between firms' debt and firms' cash flow, as described in section 5.5. We identify the $40 \%$ of firms with the highest debt payments to cash flow ratio as those facing a higher threat of bankruptcy and allow the coefficients on the competition index to vary for these firms. In Figure 16 we show the relationship between product market competition and innovation for

\footnotetext{
${ }^{34}$ We use additional instruments that vary at the industry-year level for the same industries in France and US. The instruments include: imports penetration; output minus costs over output; estimate of markup from Martins et al (1996) interacted with a time trend; TFP; R\&D intensity. All instruments vary over industry and time and are included in levels and squared terms.

${ }^{35}$ The results are available from the authors.
} 
each of these two groups ${ }^{36}$ (as before the solid line is the baseline exponential quadratic specification for all firms).

Figure 16 and the numerical results presented in Table 4c show, first that firms with higher financial pressure innovate more on average than those with lower financial pressure, as predicted by the theory; and second, that the escapecompetition effect dominates over a larger range of values for the competition index for high financial pressure firms.

\section{Conclusions}

This paper has investigated the relationship between product market competition and innovation. A Schumpeterian growth model was developed in which firms innovate 'step-by-step', and where both technological leaders and their followers engage in R\&D activities. In this model, competition may increase the incremental profit from innovating; on the other hand, competition may also reduce innovation incentives for laggards. This model generates four main predictions which we test empirically. First, the relationship between product market competition (PMC) and innovation is an inverted U-shape: the escape-competition effect dominates for low initial levels of competition, whereas the Schumpeterian effect dominates at higher levels of competition. Second, the equilibrium degree of technological 'neck-and-neckness' among firms should decrease with PMC. Third, the higher the average degree of 'neck-and-neckness' in an industry, the steeper the inverted-

\footnotetext{
${ }^{36}$ We have allowed the intercept and the coefficients on the competition measure and its square to vary across the groups.
} 
$\mathrm{U}$ relationship between PMC and innovation in that industry. Fourth, firms may innovate more if subject to higher debt-pressure, especially at lower levels of PMC.

Our empirical results confirm the existence of an inverted U-shaped relationship between product market competition and innovations, which in turn indicates that some kind of an escape-competition effect should dominate at lower levels of PMC as measured by the Lerner index, whereas the Schumpeterian effect pointed out in earlier endogenous growth models and before that in the IO literature, should dominate at high initial levels of PMC. Our results also indicate a similar inverted U-shaped relationship at the industry level, and that it tends to be steeper for firms that are in more neck-and-neck industries. Finally, we find that firms facing a higher threat of bankruptcy are subject to a stronger escape-competition effect and innovate more on average, especially at lower levels of competition.

An important extension would be to introduce entry and entry threat as alternative (or complementary) measures of competition. This again would be done using an extension of the above model with entry and exit in any industry. Preliminary simulations performed on this extended model suggest an inverted U-shaped relationship between potential entry and the innovation rate.

\section{A. Appendix}

Here we provide the details of two reasons for believing that the average Lerner index of a random sample of firms in an industry should be a decreasing function of the $\alpha$ measure of competition.

The first reason is that for the special case when $\gamma$ is close to 1 then the average of the 2 Lerner indexes in an industry with any lead size $m$ is well approximated by $\frac{1-\alpha}{1-\alpha / 2}$, which is the Lerner of a neck-and-neck firm and is strictly decreasing in $\alpha$. The proof of this proposition goes as follows. 
As asserted in the text, the Lerner index of a firm with lead size $m$ is:

$$
L_{m}=\frac{1-\alpha}{1-\alpha \lambda\left(\gamma^{-m}, \alpha\right)} \equiv \widetilde{L}\left(\gamma^{-m}, \alpha\right)
$$

where $\lambda(z, \alpha)$ is the market share of a firm with relative cost $z$, defined implicitly by equations (2.5) and (2.6) of the text. When $m=0$ the proposition holds exactly:

$$
L_{0}=\frac{1-\alpha}{1-\alpha / 2}
$$

because $\lambda(1, \alpha)=1 / 2$. So suppose $m \lessgtr 0$. Taking a Taylor expansion around $\gamma=1$ and defining $\varepsilon \equiv \gamma-1$, we have:

$$
L_{m}=L_{0}-\left.\varepsilon m \frac{\partial \widetilde{L}(z, \alpha)}{\partial z}\right|_{z=1}+O\left(\varepsilon^{2}\right)
$$

Therefore the average of the two firms' Lerner indexes is:

$$
\left(L_{m}+L_{-m}\right) / 2=L_{0}+O\left(\varepsilon^{2}\right)=\frac{1-\alpha}{1-\alpha / 2}+O\left(\varepsilon^{2}\right) .
$$

So, when gamma is small, whatever the distribution of $m$, the expected Lerner of a randomly selected firm is approximately the same decreasing function of alpha.

The second reason is that even when $\gamma$ is not small, when you sample firms whose lead sizes are distributed according to the steady state distribution $\mu$ of the theory, numerically the expected value of the randomly selected firm's Lerner is a decreasing function of $\alpha$. This is illustrated below in Figure A1, which plots the expected value of a firm's Lerner index under the distribution $\mu$ against the industry's $\alpha$. The parameter values are the same as those underlying Figures $2 \sim$ 5 in the text. Figure A1 also plots the approximate value $\frac{1-\alpha}{1-\alpha / 2}$ analyzed in the preceding paragraphs, which continues to be the actual Lerner index of a neckand-neck firm, and which continues to approximate the theoretical prediction of the average Lerner fairly closely when $\alpha$ is small.

\section{B. Policy instruments}

\section{B.1. Single $M$ arket Program}

The EU Single Market Programme (SMP) is used as an exogenous policy instrument that affected the degree of product market competition. The aims of 
the SMP were to bring down internal barriers to the free movement of goods, services, capital and labor. The European Commission's White Paper (1985) outlined around three hundred specific measures which were designed to achieve this.

The measures that were aimed at promoting competition include instituting common rules on regulation, takeovers, state assistance to industry, patents and copyrights, company accounting and disclosure of information, opening up of public procurement to competitive tender and reducing intervention in agriculture. This wide range of measures impacted upon different industries differentially. The Cecchini report attempted to quantify the size of non-tariff barriers in existence before the SMP was implemented. They use a series of surveys and technical papers to assign numerical values to the size of non-tariff barriers in each industry before the SMP. Industries are divided into three categories by the Cecchini report (the classification used here is from Mayes and Hart (1994, p53) of 3-digit industries that were likely to be affected by the SMP): (i) barriers were low pre-SMP so the impact of the SMP was expected to be low; (ii) an intermediate level of barriers pre-SMP and where the measures undertaken as part of the SMP were expected to significantly reduce them: 247 Glass, 248 Refractory and ceram, 251 Basic industrial chemicals, 321 Agricultural machine, 322 Metal-worked machine, 323 Textile machinery, 324 Processing machinery, 327 Machinery for wood, 346 Domestic electric appliances, 347 Electric lamps, 351 Motor vehicles, 352 Motor vehicle bodies, 353 Motor vehicle parts, 427 Brewing and malting, 428 Soft drinks, 431 Woollen, 432 Cotton and silk, 438 Carpets, 451 Footwear, 453 Clothing, 455 Household textiles, 481 Rubber; (iii) those where there were high level of barriers pre-SMP and the SMP was expected to significantly reduce them: 256 Specialized chemicals, 257 Pharmaceutical products, 325 Mining and construct, 326 Power transmission equipment, 328 Other machinery, 330 Office machinery, 330 Manufacture of office, 341 Insulated wires, 342 Basic electrical equipment, 344 Telecomm equipment, 345 Other electronic equipment, 361 Shipbuilding, 362 Railway and tramway, 371 Precision instrument, 372 Medical equipment, 373 Optical instruments, 421 Ice cream chocolate, 491 Jewellery, 494 Toys and games.

The initial SMP programme was announced in 1986 and implementation was scheduled to take place starting in 1988 and be completed by 1992 (although not all proposals had been implemented by 1992). Thus three time periods are considered: 1980-1987, pre-SMP; 1988-1992, during implementation of SMP; 1993-1997, after SMP implemented.

Griffith (2001) uses plant level data in the UK to show that the impact of the SMP was to increase product market competition (bring down the Lerner Index) in those industries that were expected ex ante to be affected. Markups in the intermediate industries came down by around $5 \%$ and in the industries with high barriers they came down by over $10 \%$. 


\section{B.2. Cars}

MMC (1982) reported on the possible existence of a complex monopoly in the wholesale supply of car parts. The report concluded that car manufacturers and importers restricted competition by requiring persons to whom they supplied car parts to acquire them exclusively from them or from sources approved by them. This limited the extent to which component manufacturers could compete with each other and with car manufacturers and importers, restricted price competition, imposed some limitation on the level of services from which the franchised sector could benefit, and restricted competition among factors. An Order ${ }^{37}$ was subsequently approved making it unlawful for car manufacturers and importers to insist on their franchised dealers buying car parts exclusively from them.

There were four major privatizations in the car industry. Jaguar, a luxury car maker, was sold in 1984 (fixed price offer of $100 \%$ of shares). Unipart, a supplier of parts and accessories to Rover, was sold in a management buyout in 1987. Leyland, a manufacturer of buses, trucks and vans, was sold in 1987 (combination of a management buyout and sale to existing firms). Rover, a vehicle manufacturer, was sold to British Aerospace in 1988.

\section{B.3. Periodicals}

MMC (1988) found that publishers of specialist magazines intended for campers climbers and walkers refused to accept advertisements containing prices and that this constituted a complex monopoly. The adverse effects were thought to be: (a) hindering or preventing readers' informed choice, (b) restriction of competition between specialist retailers and mail order companies, (c) narrowing of price ranges and increase of average price level. An Order $^{38}$ prohibiting such actions was implemented.

\section{B.4. B rewing}

MMC (1989) found a complex monopoly in the brewing industry. The adverse effects were identified as: a) inhibition of new entry; b) reduced competition; c) higher or discriminatory prices; d) reduced consumer choice; e) restrictions on the independence of tenants of pubs; f) pricing structure which adversely affected wholesalers.

Action taken ${ }^{39}$ requiring national brewers to free half of their premises in excess of 2000 from ties. This meant that pubs were able to choose a guest beer. This applied to all brewers ensuring easy exit from loan ties, requiring brewers to

\footnotetext{
${ }^{37} \mathrm{HC}$ Hansard 24, 26-May-82, c 314-315 ORDERS SI 1982 : 1146 The Restriction On Agreements (Manufacturers And Importers Of Motor Cars) Order

${ }^{38}$ ORDERS SI 1988 : 1017 The Restriction on Conduct (Specialist Advertising Services) Order

${ }^{39}$ ORDERS SI 1989 : 2258 The Supply of Beer (Loan Ties, Licensed Premises and Wholesale Prices) Order; SI 1989 : 2390 The Supply of Beer (Tied Estate) Order.
} 
supply beer at maximum published wholesale prices, and stopped brewers selling premises with conditions that prevented them from being used as a pub in the future. There was a review of the licensing system to see whether magistrates should in future only take account of whether applicants are "fit and proper. Following consultation with the EC two Orders were passed. The Tied Estate Order was concerned with measures applying to national brewers, in particular national brewers were required to free half of their premises in excess of 2,000 from ties by 1.11.92, also, all those tied by national brewers, whether through loan ties or tenancies, were to be free to choose a guest beer, low alcohol beer, soft drinks and some other drinks from any source by 1.5.90. The Loan Ties, Licensed Premises and Wholesale Prices Order applied to all brewers and ensured easy exit from loan ties, required brewers to supply beer at maximum published wholesale prices and stopped brewers selling premises with conditions that prevented them from being used as pubs in the future. The impact of these orders on firms pricing behavior has subsequently been studied by Slade (2001).

\section{B.5. Telecoms}

Cable and Wireless, a major international telecommunications company, was privatized in 1981. This happened through a fixed price offering of $49.4 \%$ of its shares in 1981, a tender offer of an additional $22.3 \%$ in 1983 and a further fixed price offer of $22.7 \%$ in 1985.

MMC (1989) investigated the proposed acquisition of The Plessey Company plc by a company jointly owned by The General Electric Company. plc (GEC) and Siemens AG. The MMC allowed the merger but found adverse effects in the form of a reduction of competition. The MMC recommended that GEC not be allowed to acquire control of some parts of Plessey's activities which should pass to Siemens only.

GEC and Siemens undertook ${ }^{40}$ a) that GEC would not acquire any control over Plessey's radar and military communications business and traffic control activities; b) that arrangements for the ownership and management of Plessey's defence, $\mathrm{R} \& \mathrm{D}$, and semiconductor businesses would be made to comply with national security requirements; c) that access to technology and licences for production of JTDIS equipment would be available to any competitor nominated by the Ministry of Defence.

\section{B.6. Textiles}

MMC (1989) investigated two merger situations involving Coats Viyella plc (Coats) and the Tootal Group Plc (Tootal). The first involved Coat's further acquisition of Tootal equity which raised its holding to 29.9 per cent, the second involved an offer for all Tootal's issued share capital. The impact of these proposed mergers

\footnotetext{
${ }^{40}$ ORDERS SI 1989 : 27 The Merger Reference (GEC, Siemens and Plessey) Order.
} 
was found to have adverse effects through: a) reduction in competition; b) higher prices; c) reduced consumer choice. The merger was allowed but Coats undertook $^{41}$ to dispose of its interest in the UK supply of domestic sewing thread and in Gutermann \& Co. Until these disposals Coats undertook to exercise no more than 9.9 percent of its voting rights in Tootal.

\section{B.7. R azors}

MMC (1991a,b) relate to concurrent references to the Commission concerning the situation arising from a leveraged buy-out of the Consumer Products (CP) division of Stora, which included the Wilkinson Sword business, using a shelf company to be called Swedish Match. Finance for the transaction was to be provided by a number of Swedish investor institutions together with the Gillette company and its subsidiaries. The reports concluded that a monopoly situation existed in favour of Gillette UK and that the affect of Gillette's involvement in the transaction, specifically the giving of assistance to and the provision of finance for Swedish Match in connection with a buy-out, was to weaken the competitiveness of its main competitor in the United Kingdom, to strengthen its competitive position, and to reduce competition. This would result in prices being higher than they would otherwise be and a reduction in consumer choice. The reports recommended that Gillette UK should dispose of its equity interests. ${ }^{42}$

\section{B.8. Steel}

British Steel, the largest UK steel producer, was privatized in 1987 through a fixed price offer of $100 \%$ of its shares.

\section{B.9. Ordnance}

Royal Ordnance, manufacturer of artillery, ammunition, explosives, ordnance, small arms and rocket motors, sold to British Aerospace in 1987.

\section{R eferences}

Aghion, P, Dewatripont, M, and P. Rey (1999), "Competition, Financial Discipline, and Growth", Review of Economic Studies, 66, 825-852.

\footnotetext{
${ }^{41}$ ORDERS SI 1989 : 1054 The Merger Reference (Coats Viyella PLC and Tootal Group PLC) Order.

${ }^{42}$ ORDERS SI 1991 : 750 The Merger Situation (Stora/Swedish Match/Gillette) (Interim Provision) Order SI 1993 : 1703 The Merger Situation (Stora/Swedish Match/Gillette) (Interim Provision) (Revocation) Order.
} 
Aghion, P, Harris, C, and J. Vickers (1997), "Competition and Growth with Stepby-Step Innovation: An Example", European E conomic Review, Papers and Proceedings, pp. 771-782.

Aghion, P, Harris, C, Howitt, P and J. Vickers (2001), "Competition, Imitation and Growth with Step-by-Step Innovation", Review of Economic Studies, vol 68, pp. 467-492.

Aghion, P., and P. Howitt (1992) "A Model of Growth through Creative Destruction." Econometrica 60, 323-51.

Aghion, P., and P. Howitt (1998) Endogenous Growth Theory. Cambridge, MA: MIT Press.

Aghion, P., and P. Howitt (2001), "Institutional Complementarity and the Design of Competition Policy", Unpublished, December.

Ai, C. and X. Chen (2000), "Efficient Estimation of Models with Conditional Moment Restrictions Containing Unknown Functions", LSE Working Paper in Econometrics, June.

Bloom, N. and Van Reenen, J. (2000), "Real Options, Patents, Productivity and Market Value: Evidence from a Panel of British Firms", Institute for Fiscal Studies working paper W00/21.

Blundell, R., Griffith, R. and Van Reenen, J. (1995), "Dynamic Count Data Models of Technological Innovation", Economic J ournal, Vol. 105, March 1995, 333344 .

Blundell, R., Griffith, R. and Van Reenen, J. (1999), "Market Share, Market Value and Innovation in a Panel of British Manufacturing Firms", Review of Economic Studies, vol. 66, 529-554.

Blundell, R., and J. Powell (2001), "Endogeneity in Nonparametric and Semiparametric Regression Models", forthcoming in L. Hansen (ed), Advances in E conometrics, vol. Econometric Monograph Series, Cambridge University Press. http://cemmap.ifs.org.uk/docs/cwp0901.pdf.

Boone, J. (12000): "Measuring Product Market Competition", CEPR Working Paper 2636.

Caballero, R and A. Jaffe (1993), "How High are the Giants' Shoulders? An Empirical Assessment of Knowledge Spillovers and Creative Destruction in a Model of Economic Growth", NBER Macroeconomic Annual, pp. 15-74. 
Cohen, W., and R. Levin, 1989 "Empirical studies of innovation and market structure", Chapter 18 of R. Schmalensee and R. Willig, Handbook of Industrial Organization, Elsevier.

Dasgupta, P. and Stiglitz, J. (1980) "Industrial Structure and the Nature of Innovative Activity", Economic J ournal, 90, 266-293.

Gale, D. and M. Hellwig (1985) "Incentive-Compatible Debt Contracts: The OnePeriod Problem", Review of E conomic Studies, 52, 647-663.

Geroski, P. (1995) Market Structure, Corporate Performance and Innovative Activity, Oxford: Oxford University Press.

Griffith, R (2001) "Product market competition, efficiency and agency costs: an empirical analysis", IFS Working Paper W02/04.

Griliches, Z (1990) "Patent Statistics as Economic Indicators: A Survey", J ournal of E conomic Literature 28, 1661-1707.

Hall, R (1988) "The relationship between price and marginal cost in U.S. industry" J ournal of Political E conomy, vol. 96, 921-47

Hall, B., Jaffe, A. and Trajtenberg, M. (2001), "Market Value and Patent Citations: A First Look", mimeo UC Berkeley.

Hausman, J., B. Hall, and Z. Griliches (1984) "Econometric Models for Count Data and an Application to the Patents-R\&D Relationship." Econometrica, 52, 909-938.

Klette, T and Griliches, Z (1996) "The inconsistency of common scale estimators when output prices are unobserved and endogenous" J ournal of Applied Econometrics 11(4), 343-361

Klette, T.J. (1999) "Market power, scale economies and productivity: Estimates from a panel of establishment data" J ournal of I ndustrial E conomics, Vol. XLVII, No. 4

Levin, R., Cohen, W. and D. Mowery (1985) "R\&D appropriability, opportunity, and market structure: new evidence on some Schumpeterian hypotheses", A merican Economic Review Proceedings, (75) 20-24.

Martins, J, Scarpetta, S and Pilat, D (1996) "Markup-up ratios in manufacturing industries: estimates for 14 OECD countries", OECD Working Paper No. 162

MMC (1982) "Car parts: a report on the matter of the existence or the possible 
existence of a complex monopoly situation in relation to the wholesale supply of motor car parts in the UK" (HC 318 1981-82)

MMC (1988) "Specialised advertising services: a report on the matter of the existence or possible existence of a monopoly situation in relation to the supply in the UK of the services of accepting advertisements for publication in specialised magazines intended for campers, climbers and walkers" (Cm 280)

MMC (1989) "The supply of beer: a report on the supply of beer for retail sale in the UK" (Cm 651)

MMC (1989) "The General Electric Co PLC, Siemens AG and the Plessey Co PLC: a report on the proposed mergers" (Cm 676)

MMC (1989) "Coats Viyella PLC and Tootal Group PLC: a report on the merger situation" (Cm 833)

Mayes, D. and P. Hart (1994) The Single Market Programme as a Stimulus to change: comparisons between Britain and Germany, Cambridge University Press: Cambridge

Newey, W. Powell, J. and Vella, F. (1999), "Nonparametric Estimation of Triangular Simultaneous Equations Models", E conometrica, 67, 565-604.

Nickell, S. (1996) "Competition and Corporate Performance", J ournal of P olitical E conomy, 104, 724-746.

Scherer, F (1967) "Market structure and the employment of scientists and engineers", American E conomic Review, 57 (3), 524-531.

Slade, M. (2001) "Assessing Market Power in UK Brewing" mimeo UBC

Townsend, R. (1979) "Optimal Contracts and Competitive Markets with Costly State Verification" J ournal of E conomic Theory, 21, 269-293. 


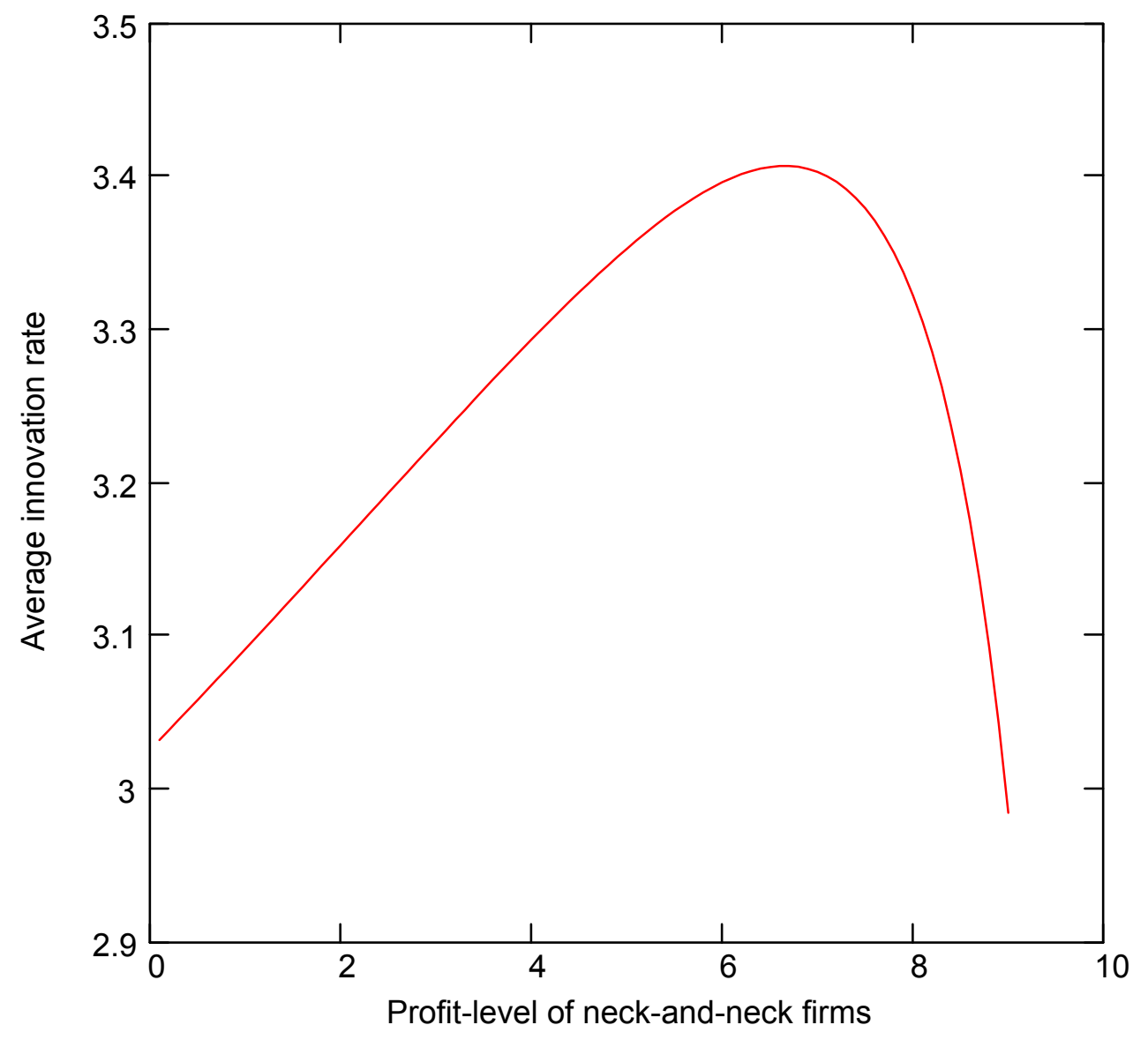

As competition decreases, the equilibrium profit level $\pi_{0}$ of neck-and-neck firms increases, resulting eventually in a fall in the economy-wide innovation rate.

Figure 1 


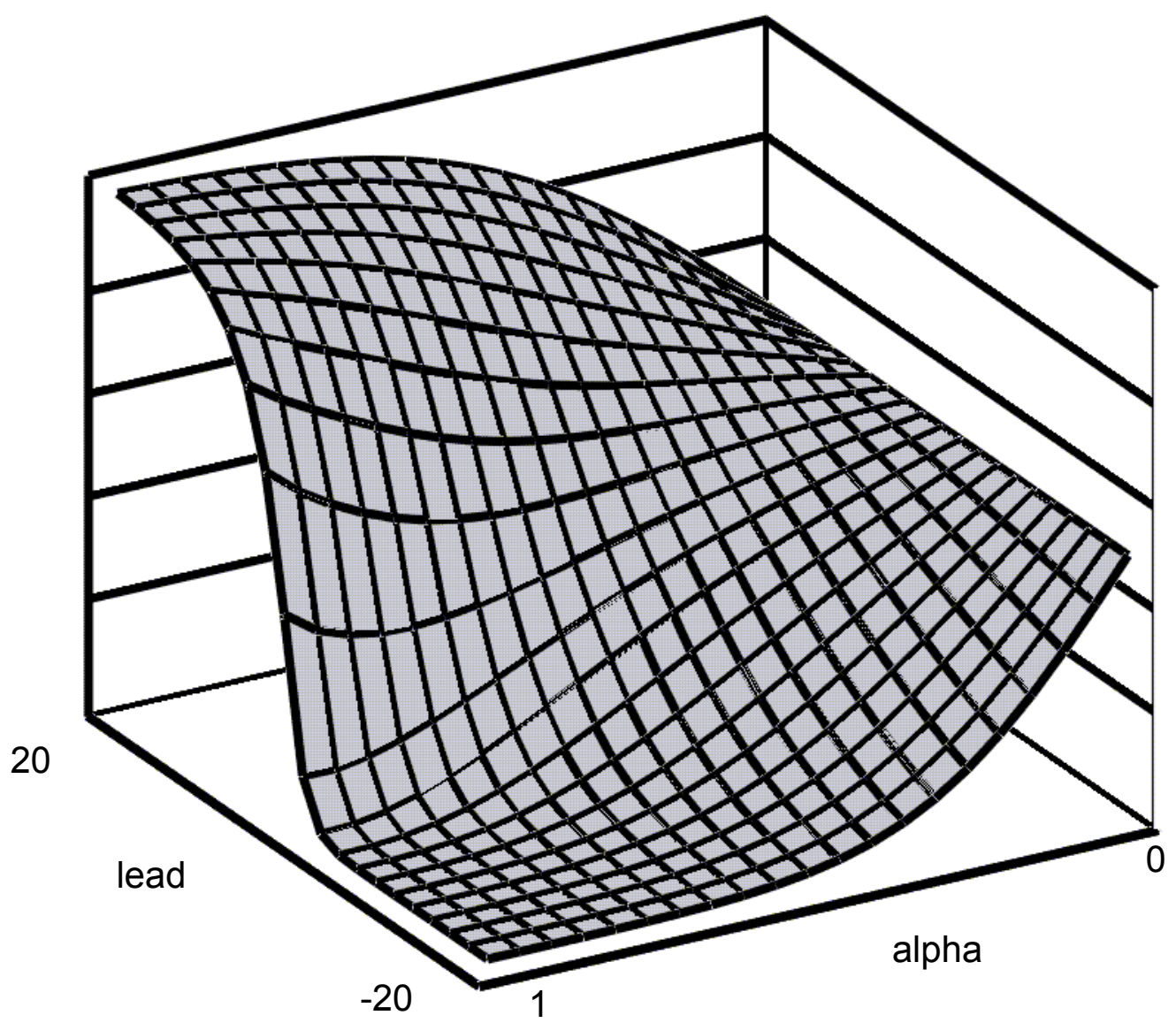

Figure 2: How a firm's value depends on its technogical lead and on the degree of product market competition 


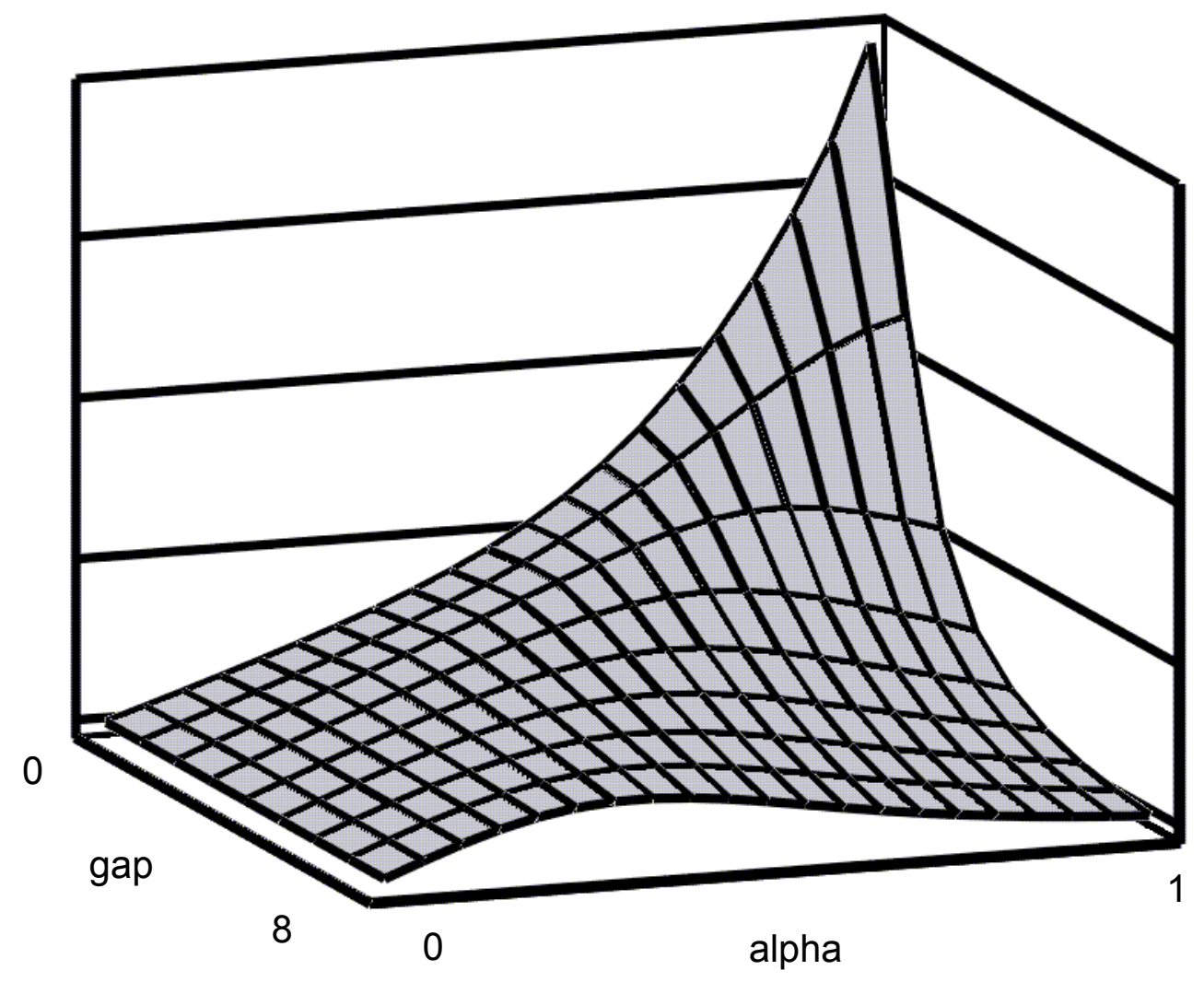

Figure 3: Total Industry R\&D as a function of the technological gap between leader and follower and of the degree of product market competition. 


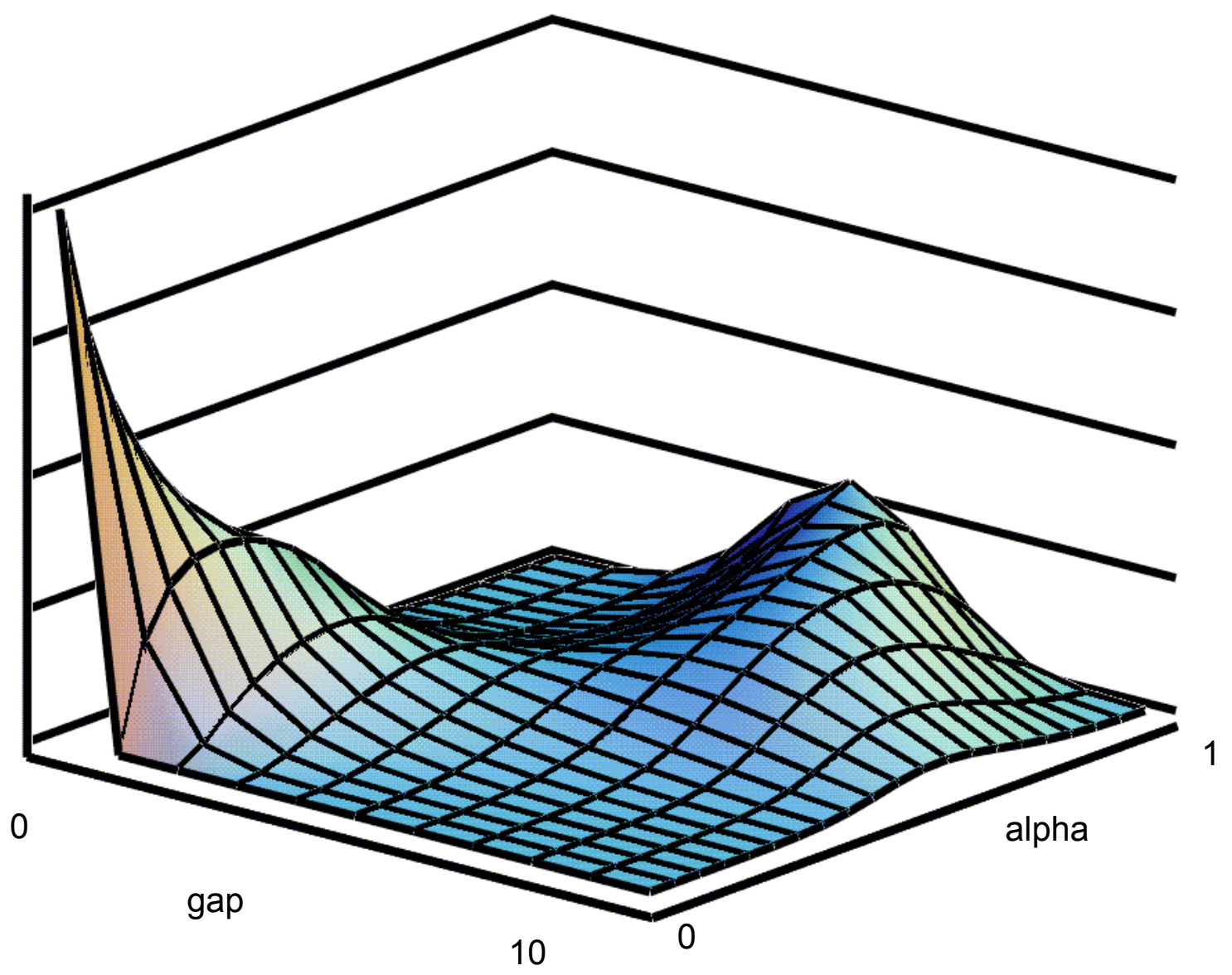

Figure 4: The cross-industry distribution of technological gaps for different degrees of product market competition 


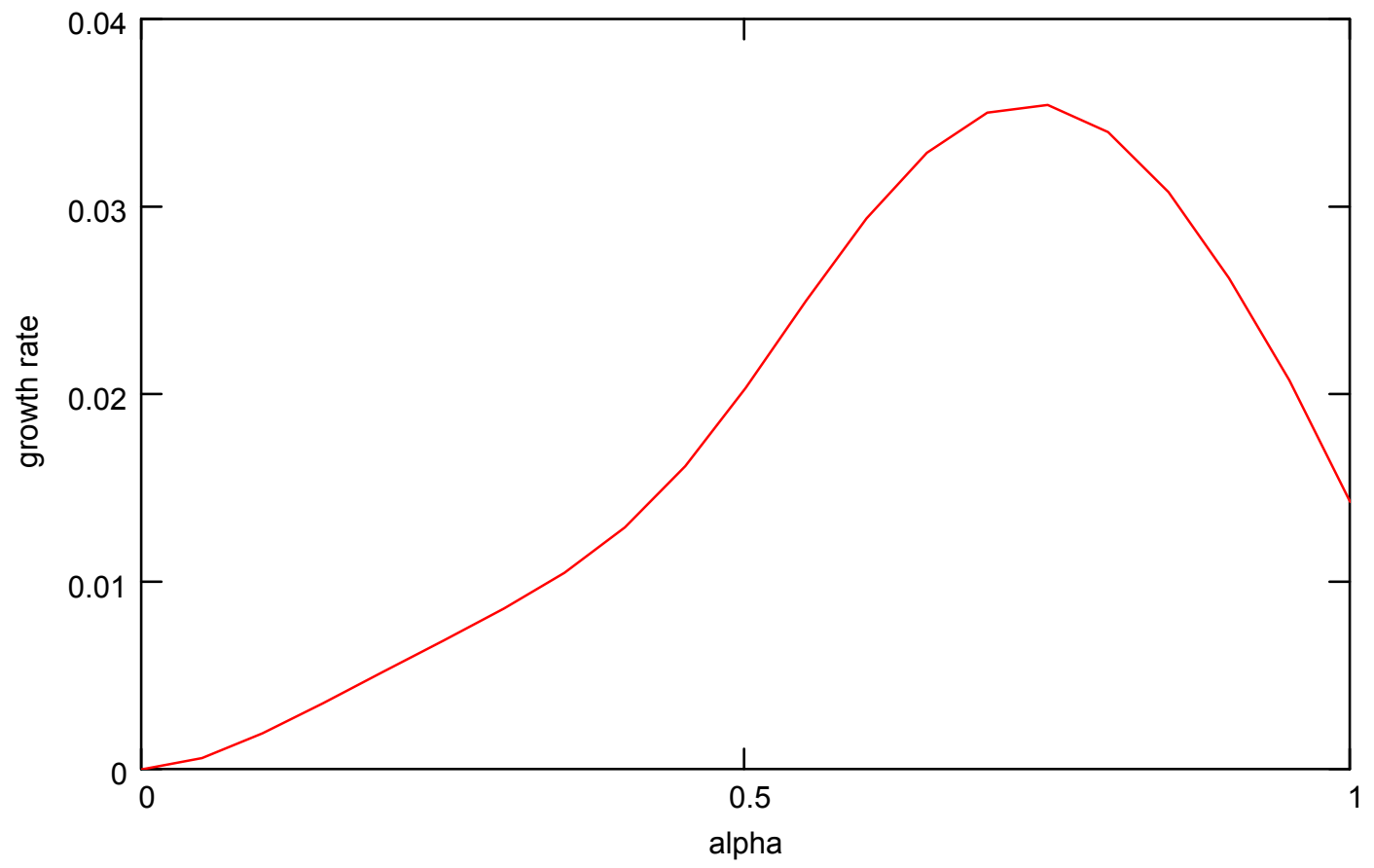

Figure 5: The effects of competition on growth 
$\mathrm{n}=0$

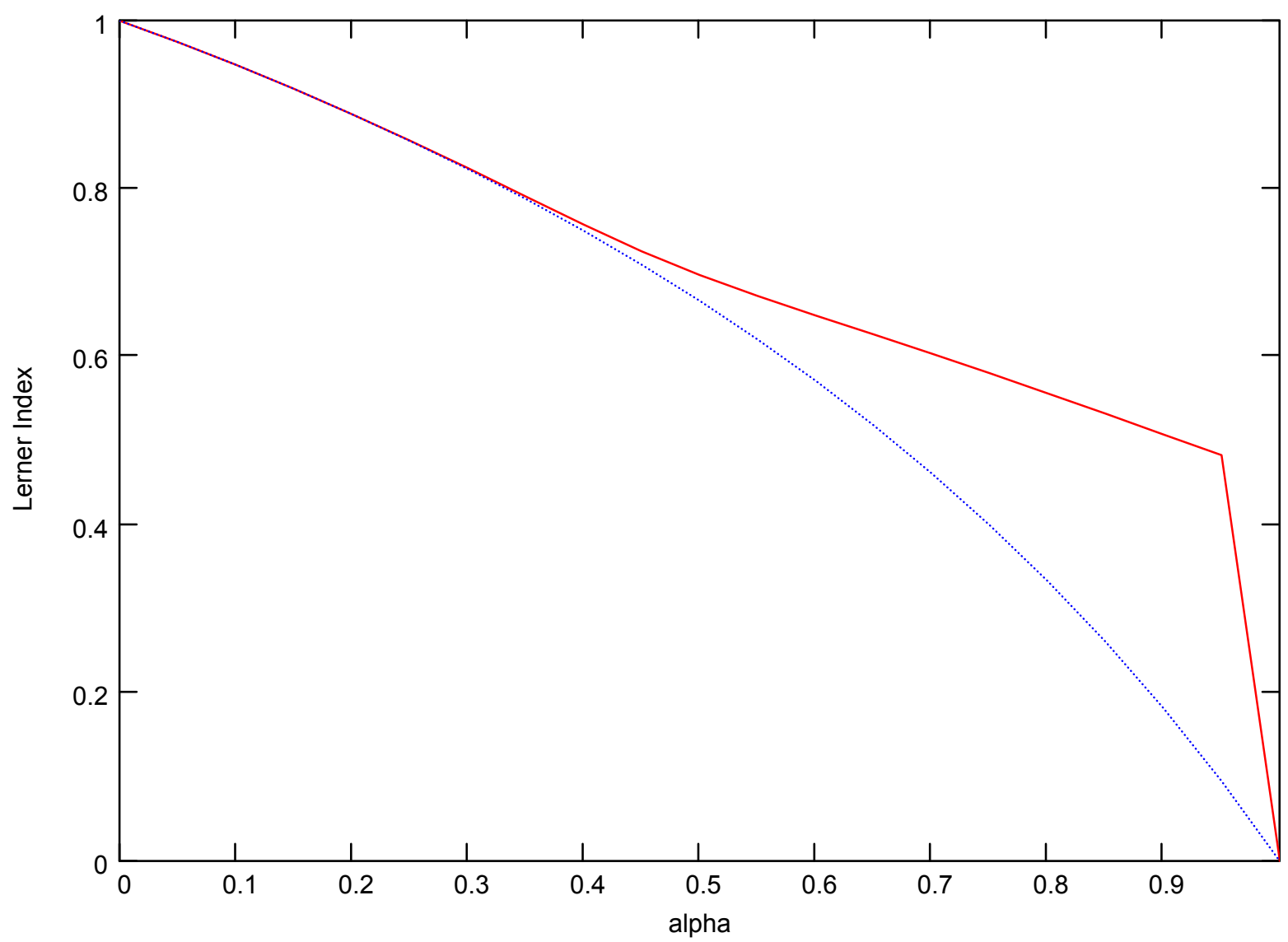

FIGURE A1. The theoretical relationship between alpha and the average firm's Lerner. The solid line shows the expected average Lerner of the two firms under the steady-state distribution implied by the theory. The dashed line shows the Lerner of a neck-and-neck firm. 


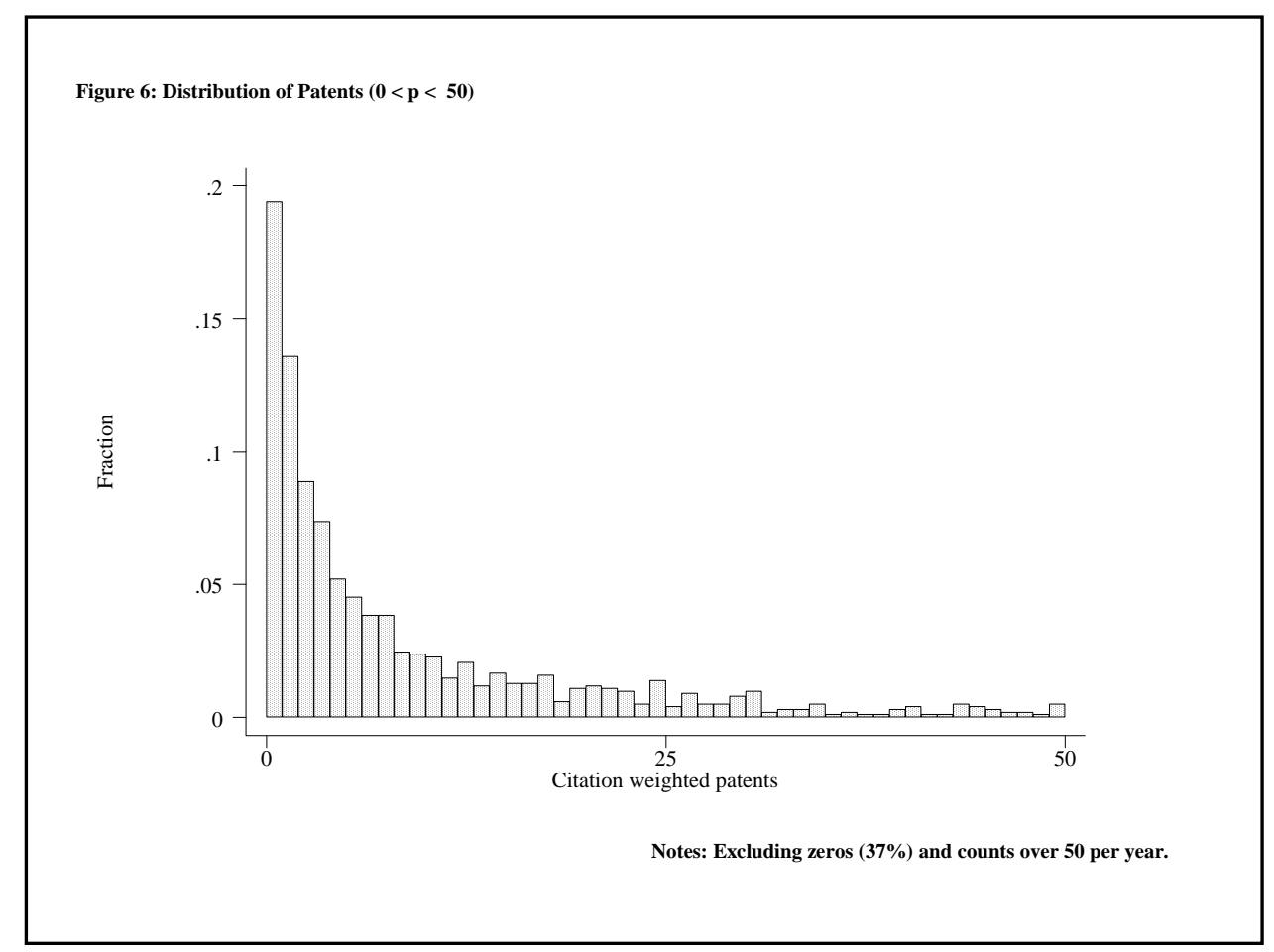

Figure 7: Measures of competition, c compared to alpha
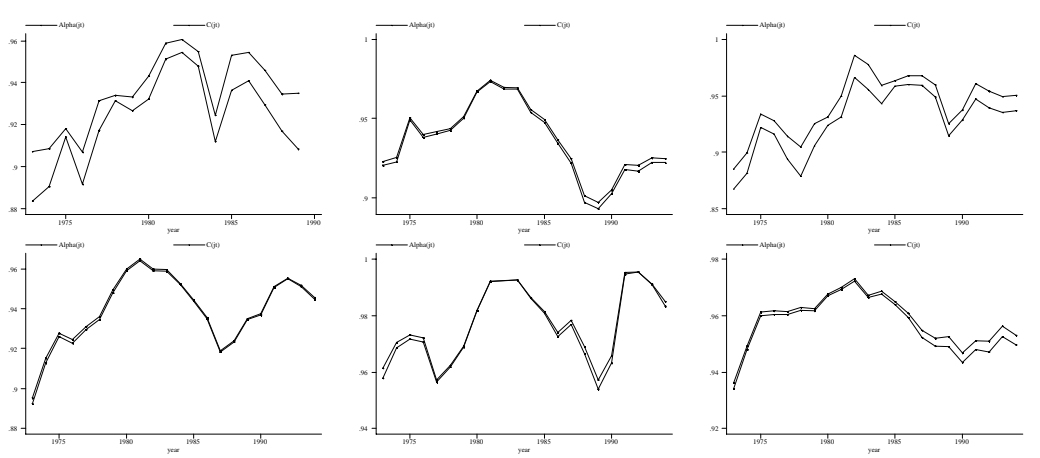
Figure 8: Innovation and Product Market Competition:

Exponential quadratic and the semiparametric specifications: with year and industry effects

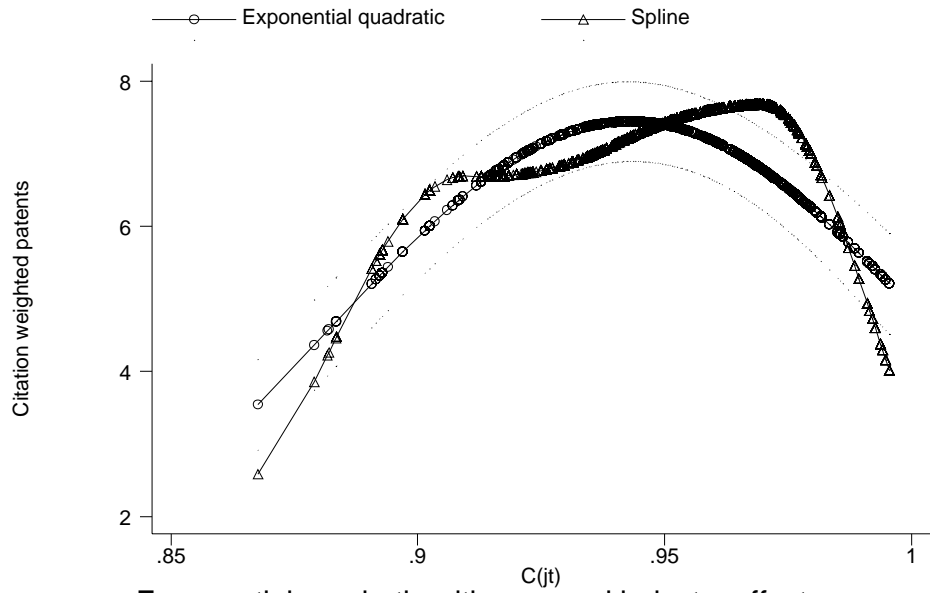

Exponential quadratic with year and industry effects

Figure 9: Innovation and Product Market Competition: Firm Level Competition Measure

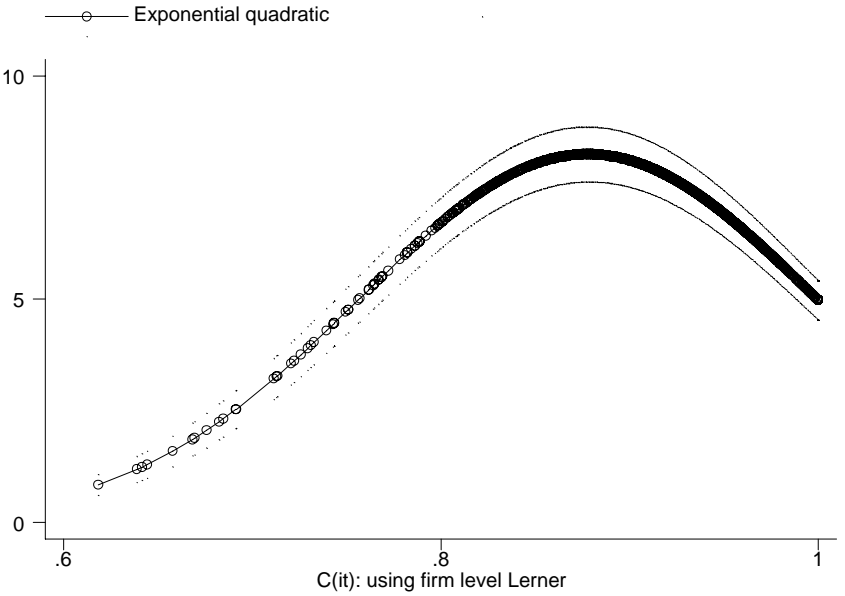


Figure 10: Innovation and Product Market Competition: Four highest patenting industries
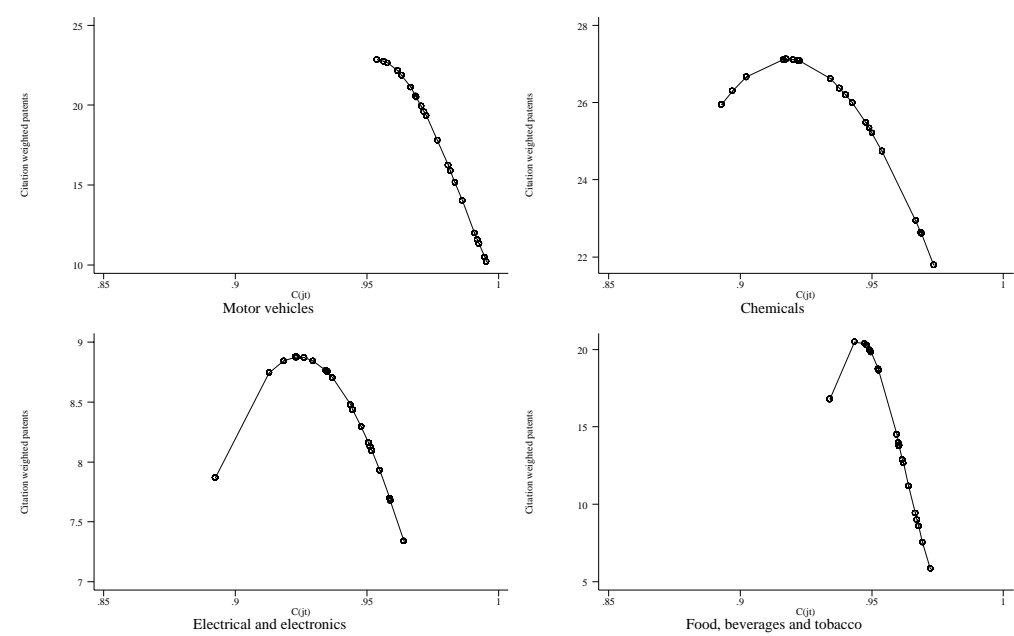

Figure 11: Innovation and Product Market Competition: Using alpha rather than 1-Lerner

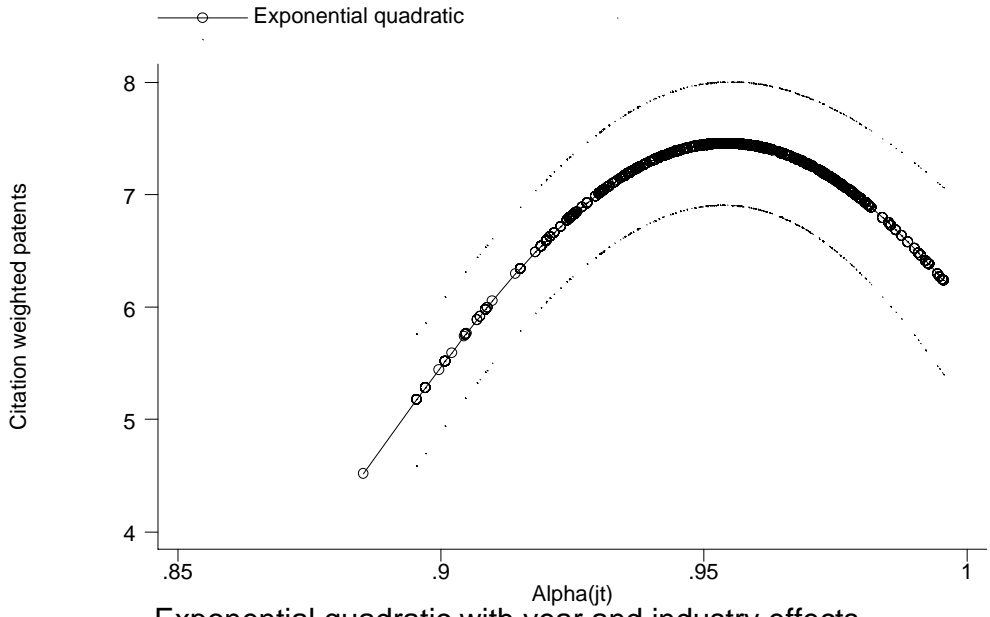

Exponential quadratic with year and industry effects 

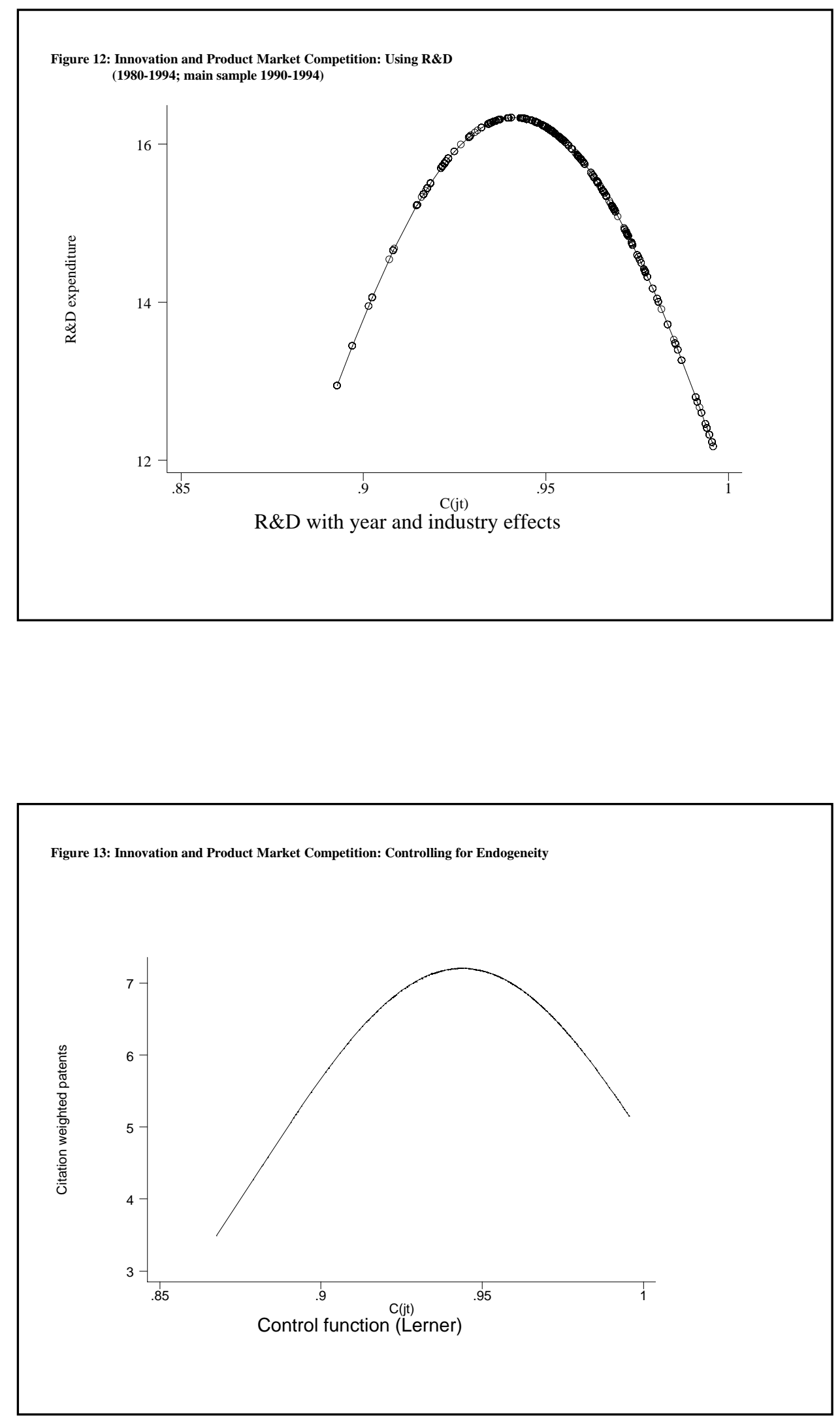


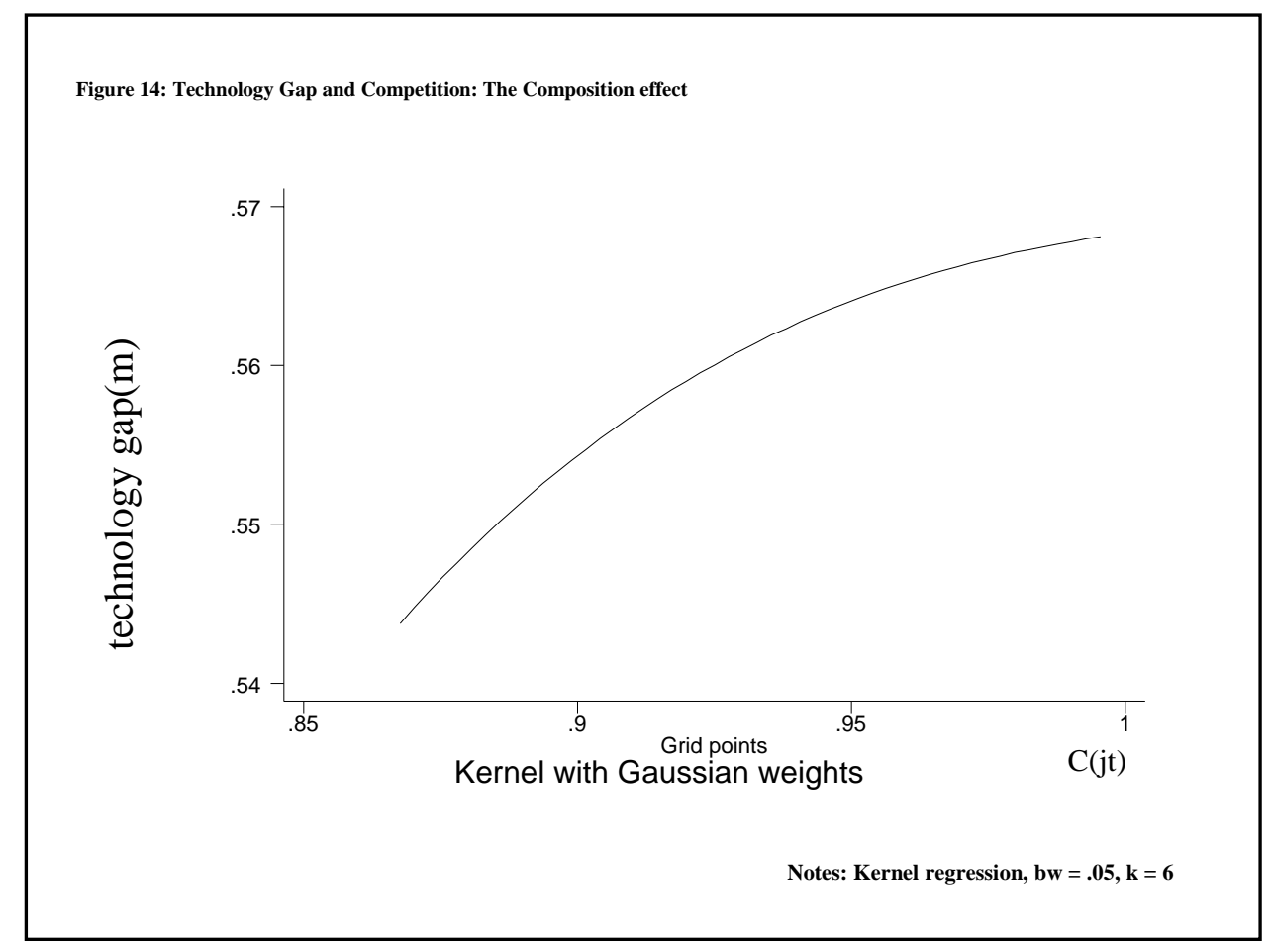

Figure 15: Innovation and Product Market Competition: The neck and neck split

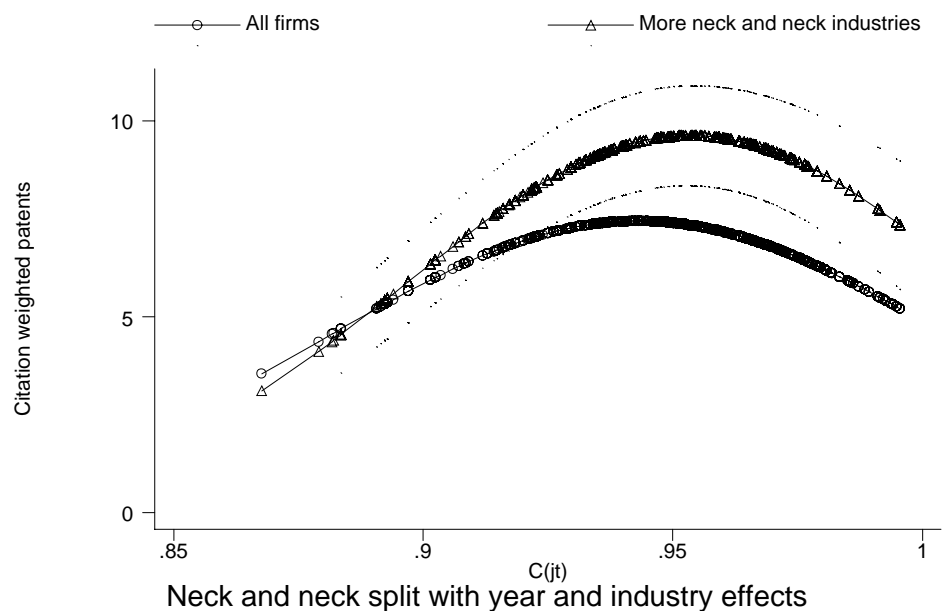

Neck and neck split with year and industry effects 
Figure 16: Innovation and Product Market Competition: The financial pressure split

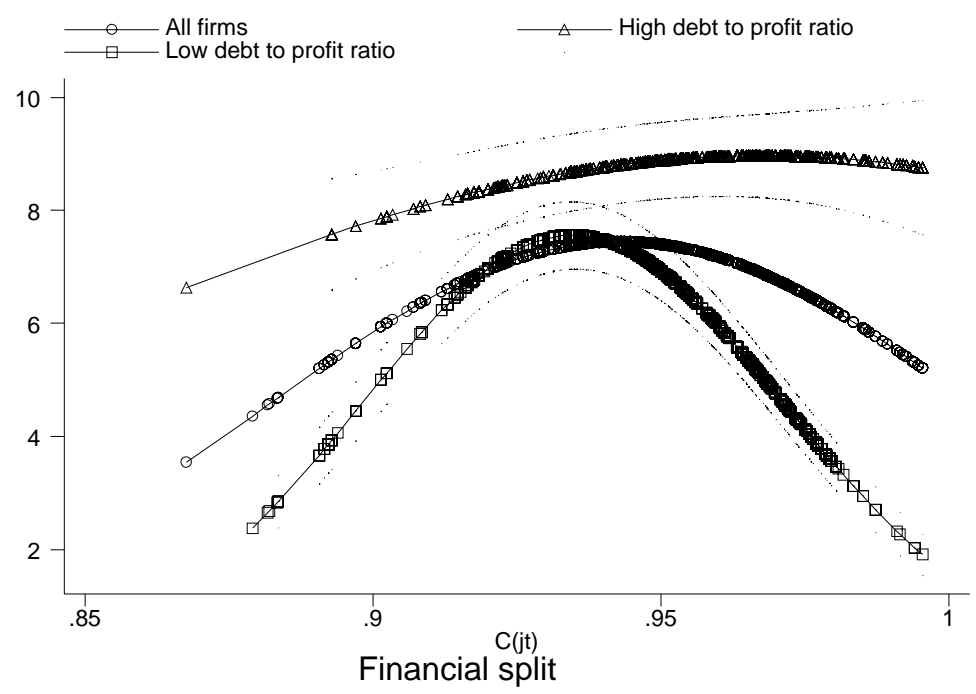


Table 1: Distribution of observations with patents data by industry

\begin{tabular}{|c|c|c|c|}
\hline Industry & $\begin{array}{c}\text { Accounting data } \\
\text { only }\end{array}$ & $\begin{array}{c}\text { Accounting and } \\
\text { patent data }\end{array}$ & Total \\
\hline \multirow[t]{2}{*}{22 Metal manufacturing } & 155 & 123 & 278 \\
\hline & 55.76 & 44.24 & 100.00 \\
\hline \multirow[t]{2}{*}{23 Extraction of other } & 17 & 34 & 51 \\
\hline & 33.33 & 66.67 & 100.00 \\
\hline \multirow{2}{*}{24 Non-Metallic Mineral } & 320 & 200 & 520 \\
\hline & 61.54 & 38.46 & 100.00 \\
\hline \multirow[t]{2}{*}{25 Chemicals } & 222 & 348 & 570 \\
\hline & 38.95 & 61.05 & 100.00 \\
\hline \multirow[t]{2}{*}{31 Manufacture of metal } & 210 & 273 & 483 \\
\hline & 43.48 & 56.52 & 100.00 \\
\hline \multirow[t]{2}{*}{32 Mechanical engineering } & 917 & 783 & 1700 \\
\hline & 53.94 & 46.06 & 100.00 \\
\hline \multirow[t]{2}{*}{33 Office \& Computing } & 72 & 31 & 103 \\
\hline & 69.90 & 30.10 & 100.00 \\
\hline \multirow[t]{2}{*}{34 Electrical and electronic } & 554 & 484 & 1038 \\
\hline & 53.37 & 46.63 & 100.00 \\
\hline \multirow[t]{2}{*}{35 Motor vehicles } & 318 & 210 & 528 \\
\hline & 60.23 & 39.77 & 100.00 \\
\hline \multirow{2}{*}{36 Manufacture of other } & 133 & 117 & 250 \\
\hline & 53.20 & 46.80 & 100.00 \\
\hline \multirow[t]{2}{*}{37 Instrument engineering } & 45 & 48 & 93 \\
\hline & 48.39 & 51.61 & 100.00 \\
\hline \multirow[t]{2}{*}{41 Food manufacture } & 209 & 112 & 321 \\
\hline & 65.11 & 34.89 & 100.00 \\
\hline \multirow[t]{2}{*}{42 Sugar Beverages \& } & 329 & 259 & 588 \\
\hline & 55.95 & 44.05 & 100.00 \\
\hline \multirow[t]{2}{*}{43 Textiles } & 458 & 310 & 768 \\
\hline & 59.64 & 40.36 & 100.00 \\
\hline \multirow[t]{2}{*}{45 Footwear and cloth } & 397 & 0 & 397 \\
\hline & 100.00 & 0.00 & 100.00 \\
\hline \multirow[t]{2}{*}{46 Wood Products \& Furniture } & 300 & 0 & 300 \\
\hline & 100.00 & 0.00 & 100.00 \\
\hline \multirow{2}{*}{47 Paper and Paper Products } & 564 & 241 & 805 \\
\hline & 70.06 & 29.94 & 100.00 \\
\hline \multirow[t]{2}{*}{48 Rubber \& Plastic } & 146 & 117 & 263 \\
\hline & 55.51 & 44.49 & 100.00 \\
\hline \multirow[t]{2}{*}{49 Other manufacturing } & 227 & 51 & 278 \\
\hline & 81.65 & 18.35 & 100.00 \\
\hline \multirow[t]{2}{*}{ Total } & 9418 & 4523 & 13941 \\
\hline & 67.56 & 32.44 & 100.00 \\
\hline
\end{tabular}


Table 2: Lerner index and patent counts by industry

\begin{tabular}{|c|c|c|c|}
\hline \multirow[b]{2}{*}{ Industry } & \multicolumn{2}{|c|}{ Average firm level Lerner Index } & \multirow[b]{2}{*}{$\begin{array}{l}\text { Average number of } \\
\text { annual patents }\end{array}$} \\
\hline & $\begin{array}{l}\text { Accounting data } \\
\text { only }\end{array}$ & $\begin{array}{l}\text { Sample with } \\
\text { accounting and } \\
\text { patent data }\end{array}$ & \\
\hline 14 Mineral oil processing & 0.074 & & 0 \\
\hline 22 Metal manufacturing & 0.060 & 0.053 & 13 \\
\hline 23 Extraction of other minerals & 0.153 & 0.183 & 9 \\
\hline 24 Non-Metallic Mineral Products & 0.077 & 0.114 & 40 \\
\hline 25 Chemicals & 0.092 & 0.100 & 330 \\
\hline 31 Manufacture of metal goods & 0.082 & 0.068 & 2 \\
\hline 32 Mechanical engineering & 0.074 & 0.076 & 55 \\
\hline 33 Office \& Computing Machinery & 0.133 & 0.111 & 8 \\
\hline $\begin{array}{l}34 \text { Electrical and electronic } \\
\text { engineering }\end{array}$ & 0.090 & 0.093 & 145 \\
\hline 35 Motor vehicles & 0.045 & 0.061 & 167 \\
\hline 36 Manufacture of other & 0.071 & 0.095 & 36 \\
\hline 37 Instrument engineering & 0.106 & 0.077 & 4 \\
\hline 41 Food manufacture & 0.060 & 0.068 & 15 \\
\hline 42 Sugar Beverages \& Tobacco & 0.104 & 0.091 & 113 \\
\hline 43 Textiles & 0.062 & 0.075 & 3 \\
\hline 45 Footwear and clothing & 0.078 & & 0 \\
\hline 46 Wood Products \& Furniture & 0.077 & & 0 \\
\hline 47 Paper Paper Products \& Printing & 0.092 & 0.085 & 3 \\
\hline 48 Rubber \& Plastic Products & 0.104 & 0.066 & 4 \\
\hline 49 Other manufacturing & 0.080 & 0.088 & 14 \\
\hline Total & 0.077 & 0.079 & \\
\hline
\end{tabular}

Table 3: Descriptive Statistics

\begin{tabular}{|c|c|c|c|c|}
\hline & $\begin{array}{c}\text { Mean } \\
\text { (s.d) }\end{array}$ & Median & Min & Max \\
\hline Patents & $\begin{array}{c}6.65 \\
(27.02)\end{array}$ & 0 & 0 & 409 \\
\hline Cite weighted patents & $\begin{array}{c}6.68 \\
(26.53)\end{array}$ & 0 & 0 & 403 \\
\hline$C(j t)$ & $\begin{array}{c}0.95 \\
(0.020)\end{array}$ & 0.95 & 0.87 & 0.99 \\
\hline Employment (1000s) & $\begin{array}{c}11 \\
(31.3)\end{array}$ & 1.2 & 0.04 & 312 \\
\hline Observations per firm & $\begin{array}{c}17.2 \\
(5.06)\end{array}$ & 19 & 5 & 22 \\
\hline Technology gap (m) & $\begin{array}{c}0.56 \\
(0.127)\end{array}$ & 0.59 & 0.085 & 0.82 \\
\hline Financial pressure & $\begin{array}{c}0.169 \\
(0.199) \\
\end{array}$ & 0.118 & 0 & 1 \\
\hline
\end{tabular}


Table 4a: Exponential Quadratic: Basic specification

\begin{tabular}{|c|c|c|}
\hline & Year and Industry Effects & Controls for Endogeneity \\
\hline Observations & 3065 & 3047 \\
\hline Constant & $\begin{array}{l}-113.8 \\
(12.41)\end{array}$ & $\begin{array}{l}-109.4 \\
(12.53)\end{array}$ \\
\hline$c_{j t}$ & $\begin{array}{c}245.5 \\
(26.52) \\
\end{array}$ & $\begin{array}{c}236.1 \\
(26.69)\end{array}$ \\
\hline$c_{j t}^{2}$ & $\begin{array}{l}-130.2 \\
(14.17) \\
\end{array}$ & $\begin{array}{l}-125.1 \\
(14.2)\end{array}$ \\
\hline \multicolumn{3}{|l|}{ Significance of: } \\
\hline$c_{j t}, c_{j t}^{2}$ & $\begin{array}{l}94.14 \\
(0.00) \\
\end{array}$ & $\begin{array}{l}79.75 \\
(0.00) \\
\end{array}$ \\
\hline year effects & yes & yes \\
\hline industry effects & yes & yes \\
\hline $\begin{array}{l}\text { significant of policy } \\
\text { instruments in reduced } \\
\text { form, LR statistic (P- } \\
\text { value) }\end{array}$ & - & $\begin{array}{l}12.17 \\
(0.00)\end{array}$ \\
\hline $\begin{array}{l}\text { significant of other } \\
\text { instruments in reduced } \\
\text { form, LR statistic (P- } \\
\text { value) }\end{array}$ & - & $\begin{array}{l}24.91 \\
(0.00)\end{array}$ \\
\hline $\begin{array}{l}\text { control functions in } \\
\text { regression }\end{array}$ & - & $\begin{array}{l}-5.99 \\
(2.69)\end{array}$ \\
\hline $\mathrm{R}^{2}$ of reduced form & - & 0.84 \\
\hline
\end{tabular}

Notes: Numbers in () are standard errors except for significance tests where they are Pvalue for test of joint significance. The significance tests show the likelihood ratio test statistic. 
Table 4b: Exponential Quadratic: Neck and Neck specification

\begin{tabular}{|l|c|c|}
\hline & Year and Industry Effects & $\begin{array}{c}\text { Controlling for } \\
\text { Endogeneity }\end{array}$ \\
\hline Observations & 1197 & 1184 \\
\hline Constant & -137.3 & -73.65 \\
& $(18.57)$ & $(19.65)$ \\
\hline$c_{j t}$ & 292.8 & 156.0 \\
& $(39.8)$ & $(42.0)$ \\
\hline$c_{j t}^{2}$ & -153.5 & -80.46 \\
& $(21.3)$ & $(22.49)$ \\
\hline Significance of: & & 22.77 \\
\hline$c_{j t}, c_{j t}^{2}$ & & $(0.00)$ \\
\hline & $(0.00)$ & yes \\
\hline year effects & & yes \\
\hline industry effects & yes & $(0.00)$ \\
\hline significant of policy & yes & 24.91 \\
instruments in reduced form & - & $(0.00)$ \\
\hline significant of other & & -5.99 \\
instruments in reduced form & - & $(2.69)$ \\
\hline control functions in regression & - & 0.84 \\
\hline & & \\
\hline $\mathrm{R}^{2}$ of reduced form & & \\
\hline & & \\
\hline & & \\
\hline
\end{tabular}

Notes: Significance test show test statistic and P-value from $\mathrm{F}$ test of joint significance. Excluded variables are: policy instruments, imports over value-added in same industryyear in USA and France, TFP in same industry-year in USA and France, output minus variable costs over output in same industry-year in USA and France, estimate of markup from industry-country regression for USA and France (Martins et al 1996) interacted with time trend. 
Table 4c: Exponential Quadratic: Financial Pressure Results

\begin{tabular}{|l|c|}
\hline Observations & 2899 \\
\hline & -323.1 \\
\hline Constant & $(20.83)$ \\
\hline$c_{j t}$ & 695.6 \\
& $(44.56)$ \\
\hline$c_{j t}^{2}$ & -372.1 \\
\hline \multirow{2}{*}{$c_{j t} *$ (financial pressure) } & $(50.00)$ \\
\hline \multirow{2}{*}{$c_{j t}^{2} *($ financial pressure) } & -637.2 \\
\hline Financial pressure & $(50.00)$ \\
\hline & 341.9 \\
& $(26.59)$ \\
\hline Significance of: & 297.0 \\
\hline$c_{j t}, c_{j t}^{2}$ & $(23.51)$ \\
\hline$c_{j t} *\left(\right.$ financial pressure), $c_{j t}^{2} *($ financial pressure $)$ & 243.88 \\
\hline year effects & $(0.00)$ \\
\hline industry effects & 228.90 \\
\hline
\end{tabular}

Notes: Significance test shows P-value from $\chi^{2}$ test of joint significance. Excluded variables are: policy instruments, imports over value-added in same industry-year in USA and France, TFP in same industry-year in USA and France, output minus variable costs over output in same industry-year in USA and France, estimate of markup from industrycountry regression for USA and France (Martins et al 1996) interacted with time trend. 